\title{
LA REVISTA ARGENTINA CIENCIA NUEVA (1970-1974): ANÁLISIS DE CONTENIDOS, RECURSOS GRÁFICOS, PUBLICIDAD Y PÚBLICOS ${ }^{1}$
}

\author{
Lic. Lucía Céspedes \\ Universidad Nacional de Córdoba, Córdoba, Argentina \\ Centro de Investigaciones y Estudios en Cultura y Sociedad (CIECS-CONICET) \\ lucicespedes27@gmail.com
}

Recibido el 1 de octubre de 2018

Aceptado el 4 de diciembre de 2018

\section{Resumen}

El objetivo de este trabajo es relevar las características de la revista Ciencia Nueva (19701974) en tanto publicación gráfica periódica dedicada a la comunicación pública de la ciencia y política científica en Argentina y América Latina, a fin de caracterizar los circuitos de comunicación científica y el contrato de lectura establecido con su lectorado (Verón, 1985, 1998). Para ello se describen las secciones fijas de la revista, su público meta, el uso de recursos gráficos, y el espacio y orden concedido a publicidad, así como las características de los anunciantes. La revista es un hito en la comunicación pública de la ciencia y la tecnología en Argentina y América Latina. Además, fue uno de los espacios donde comenzó a cristalizar la corriente de pensamiento que en retrospectiva se denominaría Pensamiento Latinoamericano en Ciencia, Tecnología y Desarrollo (PLACTED). Temas como (sub)desarrollo, dependencia, autonomía, política científicotecnológica, educación superior, o intervención estatal en ciencia son debates que hoy en día tienen plena vigencia, y que Ciencia Nueva contribuyó a colocar en la agenda pública en la década de los '70. Por lo tanto, consideramos que este estudio exploratorio puede ser la base para un análisis más profundo de los contratos de lectura de publicaciones pasadas y actuales dedicadas a la comunicación pública de la ciencia, incluyendo sus debates políticos, epistemológicos e ideológicos.

Palabras clave: Comunicación Pública De La Ciencia, Revista Ciencia Nueva, PLACTED, Contrato De Lectura.

\footnotetext{
${ }^{1}$ El presente trabajo forma parte de una investigación realizada como Trabajo Final Integrador para la Especialización en Comunicación Pública de la Ciencia y Periodismo Científico (Facultad de Matemática Astronomía, Física y Computación-Facultad de Ciencias de la Comunicación, Universidad Nacional de Córdoba, Argentina), bajo la tutoría del Dr. Diego Hurtado de Mendoza.
} 


\title{
ARGENTINIAN MAGAZINE CIENCIA NUEVA (1970-1974): AN ANALYSIS OF ITS CONTENTS, GRAPHIC RESOURCES, ADVERTISING, AND READERSHIP
}

\begin{abstract}
The aim of this paper is to assess the traits of Ciencia Nueva magazine (1970-1974) as a periodical dedicated to public communication of science and science policy in Argentina and Latin America, in order to characterize the scientific communication circuits and reading contract established (Verón, 1985, 1998). We describe the magazine's regular sections, target audience, use of graphic resources, and advertising. This periodical is a milestone in the development of public communication of science in Argentina and Latin America. Ciencia Nueva was crucial in the consolidation of what would become known as Latin American Thought on Science, Technology and Development. Even now, topics such as (under)development, dependency, autonomy, science and technology policy, higher education, or state intervention in science, are hotly debated in the region. In the '7os, Ciencia Nueva helped place these issues into the public agenda. We thus believe this exploratory study can be the onset of deeper analyses on the reading contracts established by past and current publications dedicated to public communication of science, including their political, epistemological and ideological debates.

Keywords: Public Communication of Science, Ciencia Nueva Magazine, PLACTED, Reading Contract.

\section{Cómo citar este artículo:}

Céspedes, L. (2019). "La Revista Argentina Ciencia Nueva (1970-1974): Análisis De Contenidos, Recursos Gráficos, Publicidad Y Públicos", en Perspectivas de la Comunicación, Vol. 12, nº 1 , pp. 281-313.
\end{abstract}




\section{Introducción}

a comunicación pública de la ciencia y la tecnología en Argentina tiene una historia de poco más de un siglo, pero es sumamente rica. Su desarrollo en Argentina ha ido de la mano de la evolución e institucionalización de la investigación científica en el país, la cual a su vez se ha visto fuertemente marcada por la orientación de las políticas estatales de ciencia y técnica en cada momento histórico. Puesto que la comunicación pública de la ciencia ${ }^{2}$ está inexorablemente ligada al estado del campo científico en un momento dado, consideramos junto con Cazaux (2010:22) que las actitudes de los sucesivos gobiernos hacia la CyT "también dejaron su huella en el desarrollo de la divulgación científica en nuestro país. Además, es indiscutible que ambos desarrollos estuvieron y están insertos en el contexto mundial de los acontecimientos". Este escenario nos motiva a analizar en este trabajo la revista Ciencia Nueva como publicación gráfica periódica dedicada a la CPC, y en relación con lo que retrospectivamente se conoce como la corriente de Pensamiento Latinoamericano en Ciencia, Tecnología y Desarrollo (PLACTED) ${ }^{3}$.

Ciencia Nueva fue una revista publicada en Buenos Aires entre los años 1970 y 1974. Se creó por iniciativa de Manuel Sadosky4, quien, a partir del contacto con un editor, en 1969 reunió un grupo de ex-estudiantes y colegas de las facultades de Ciencias Exactas y Naturales e Ingeniería de la Universidad de Buenos Aires con la propuesta de hacer una revista de divulgación científica. La mayoría de ellos acababan de volver a la Argentina luego de becas, intercambios o estancias de perfeccionamiento en centros científicos de Estados Unidos y Europa, pero también luego de exilios por razones políticas (ya fueran diferencias con el peronismo antes de 1955 o con los regímenes cívico-militares antiperonistas luego de ese año, o el efecto de la "Noche de los Bastones Largos" en 1966).

En aquel entonces prácticamente no existían publicaciones similares en español dentro de América Latina, aunque en décadas pasadas había comenzado a consolidarse en Argentina una práctica editorial desde asociaciones científicas nacionales. Estas publicaciones, si bien disponibles para el público general, estaban dirigidas a la propia comunidad científica como órganos de comunicación endógena o exógena, o bien tenían la intención de ser una plataforma de reclamos de los científicos argentinos, que esperaban hacer eco en la clase política e industrial del país. Por otra parte, Argentina contaba con una importante tradición en materia de edición de libros de ciencias, principalmente de corte pedagógico, destinados a todo público. Se destacan en este rubro las colecciones Naturaleza (Códex), Esquema (Columba), y Cuadernos (Eudeba), entre otras (Cazaux, 2010).

\footnotetext{
2 En adelante, CPC (remitimos a la discusión sobre esta denominación en el apartado siguiente).

3 Esta tradición también se ha llamado "Pensamiento Latinoamericano en Ciencia, Tecnología y Sociedad" (PLACTS). En este trabajo adoptaremos la denominación PLACTED, dado que uno de los principales puntos de discusión entre los autores considerados era las tensiones entre modelos de desarrollo impuestos o autónomos. Así también se evita identificar esta corriente de pensamiento con el campo académico de los estudios CTS (Ciencia, Tecnología y Sociedad), que en América Latina comienza a institucionalizarse en los años '80 y a consolidarse en los ' 90 .

4 Matemático, físico e informático argentino. Fue Vicedecano de la Facultad de Ciencias Exactas y Naturales de la Universidad de Buenos Aires (1957-1966) y Secretario de Ciencia y Tecnología de la Nación durante la presidencia de Raúl Alfonsín (1983-1989).
} 
Sin embargo, se encuentran pocas experiencias previas de revistas concebidas como publicaciones periódicas de divulgación científica. Como antecedentes, pueden mencionarse Ciencia e Investigación ${ }^{5}$, publicada por la Asociación Argentina para el Progreso de las Ciencias "con el objetivo de llegar a la opinión pública para difundir su propia representación del campo científico y su diagnóstico escéptico de la realidad científica local" (Hurtado y Feld, 2010:6); y Mundo Atómico (1950-1955), revista de divulgación científica impulsada por el gobierno de Juan Domingo Perón que exponía "las líneas de fuerza seleccionadas por el oficialismo para difundir su visión acerca del lugar político de la ciencia y la técnica en la Nueva Argentina" (Hurtado y Feld, 2010:6).

Ciencia Nueva no se limitó a cubrir los acontecimientos nacionales e internacionales dentro del campo de las ciencias "duras". Desde su primera edición, la retiración de tapa de la revista anunciaba que expondría "las teorías generales, [...] el planteo, el desarrollo y la discusión de la investigación contemporánea, en todos los dominios [...] los problemas de política científica [...] los problemas que la ciencia resuelve, y los problemas que la ciencia crea." (CN\#1, 1970). A lo largo de sus 29 ejemplares, Ciencia Nueva se constituyó como un espacio de difusión de noticias y conocimiento científico, pero también de debates políticos, epistemológicos e ideológicos.

Tanto por la talla de sus autores (en ella se publicaron textos de Jorge Sábato, Amílcar Herrera, Oscar Varsavsky, Jorge Katz, Enrique Oteiza, Gregorio Klimovsky, Rolando García, o Mario Bunge, entre otros destacados científicos e intelectuales) como por la profundidad y diversidad de temas que trataba, Ciencia Nueva constituye un mojón ineludible en la historia de la CPC en Argentina y en América Latina. Temas como (sub)desarrollo, dependencia, autonomía, política científico-tecnológica, educación superior, o intervención estatal en ciencia, son debates que hasta el día de hoy tienen plena vigencia en la región, y que, en gran medida, irrumpieron en la agenda pública en la década de los '7o.

Esta localización temporal no quiere decir que la revista y sus temáticas hayan perdido vigencia; al contrario, Ciencia Nueva ha sido digitalizada y se encuentra disponible para su consulta online en la plataforma Políticas CTI, una iniciativa llevada adelante por el Observatorio Iberoamericano de la Ciencia, la Tecnología y la Sociedad (OCTS) perteneciente a la Organización de Estados Iberoamericanos (OEI) en conjunto con la Red de Indicadores en Ciencia y Tecnología Iberoamericana e Interamericana (RICYT). EI PLACTED, por su parte, resurgió con mucha vitalidad en América Latina durante la primera década de los 2000, en el marco de gobiernos progresistas que colocaron a la CyT en el centro de estrategias conjuntas para romper con las imposiciones del orden mundial neoliberal sobre la región. La reedición de obras centrales de esta corriente por parte de la Biblioteca Nacional de Argentina fue una importante toma de posición en pos de reimpulsar el pensamiento crítico nacional y latinoamericano sobre ciencia y tecnología, proceso que en el país cesa y se revierte a partir de 2015.

\section{Metodología de análisis}

Entendemos el concepto de CPC en el sentido amplio postulado por Alcíbar (2015:3), para quien "comunicación pública de la ciencia" es una noción paraguas que abarca "todas

5 Ciencia e Investigación fue fundada en 1945 y, si bien atravesó etapas de distinta periodicidad, actualmente se sigue publicando. Desde 2003 se edita en forma electrónica. 
aquellas actividades con las que la cultura científica se incorpora a la cultura popular". Para aplicar una definición tan general al objeto de estudio (una producción de prensa gráfica), distinguiremos al periodismo científico de la divulgación científica. ${ }^{6}$ Siguiendo al autor, el término "CPC" incluye y abarca ambas acepciones. El primero constituye una rama especializada del periodismo, y como tal se caracteriza por las condiciones de producción que corresponden a los medios masivos de comunicación. El periodismo científico adhiere a los valores periodísticos generales de rigor, precisión, diversidad de fuentes, y selección de temas según criterios de noticiabilidad, entre los que el más determinante es la actualidad del hecho noticiable. Por el contrario, en la divulgación científica los temas son más "atemporales", ya que "se centra en hacer accesibles contenidos estrictamente científico-técnicos" (Alcíbar, 2015:3) para un público más concreto. Alcíbar plantea que en la divulgación podemos encontrar científicos e investigadores como emisores de mensajes, mientras que en el periodismo el lugar del emisor es ocupado por el periodista o comunicador. Como veremos, ambas modalidades de CPC se encuentran en Ciencia Nueva.

Con respecto a los sujetos involucrados en la CPC, seguimos las conceptualizaciones de Eliseo Verón (1998) acerca de los circuitos de comunicación científica. Verón distingue cuatro situaciones comunicativas, que van de mayor homogeneidad y clausura del circuito a mayor heterogeneidad y apertura, en función de quiénes ocupan los roles de enunciador y enunciatario. El autor identifica, por un lado, los circuitos de comunicación endógena intra e interdisciplinar. En ambos casos el enunciador es un científico experto que comunica un mensaje a colegas de su misma área de trabajo o de diferentes disciplinas. Tanto enunciador como enunciatario se definen como parte de la comunidad científica y poseen competencias equivalentes. La situación comunicativa se justifica y encuentra su origen en esa paridad.

Por otro lado, el circuito de comunicación en el que el enunciador es un experto, miembro de una determinada comunidad científica, y el enunciatario no lo es, se denomina comunicación endógena transcientífica. Enunciador y enunciatario se definen aquí por la diferencia en sus competencias, y es en función de esa diferencia que el enunciador se erige con legitimidad para tomar la palabra en materia de ciencia. Finalmente, cuando la comunicación no involucra participantes de una comunidad científica, estamos ante la comunicación exógena sobre la ciencia. En esta situación ni enunciador ni enunciatario se definen como productores de conocimiento. Sin embargo, el enunciador, típicamente un comunicador social o periodista, "se construye más o menos explícitamente como posesor de más conocimientos que el destinatario al que se dirige" (Verón, 1998:155). Esta complementariedad legitima y da inicio al acto comunicativo.

Verón (1985) también plantea que todo medio gráfico establece un contrato de lectura con su lectorado. Vínculo establecido entre un soporte de prensa y su lectura, el contrato es propuesto por el medio y realizado a través de diferentes estrategias de enunciación: titulación, relación texto-imagen, paginación, ordenamiento del material, "y todas las otras dimensiones que puedan contribuir a definir de modo específico los modos en que el soporte constituye el nexo con su lector" (Verón, 1985:6). Esto es, el contrato de lectura va más allá de lo que se dice (nivel del enunciado) para atender a las modalidades del decir (nivel de la enunciación). Estas modalidades dan forma al contrato de lectura en tanto dispositivo

${ }^{6}$ Estas divisiones, por supuesto, son analíticas y en la realidad no se dan de modo puro. 
de enunciación que incluye simultáneamente la imagen del que habla (imagen que el enunciador se atribuye a sí mismo e implica una relación de éste con lo que dice), la imagen del destinatario, y la relación entre ambos. La eficacia de un contrato de lectura se mide por la capacidad de un medio de crear expectativas en su lectorado y de cumplirlas posteriormente, pero también por su habilidad para evolucionar y modificarse de forma coherente, para mantener el vínculo con los lectores.

Por todo lo antes dicho, el objetivo de este trabajo es relevar las características formales de la revista Ciencia Nueva en tanto medio gráfico dedicado a la CPC y el debate sobre política científica, a fin de caracterizar el contrato de lectura establecido con sus lectores. Verón (1985:6) plantea que, en esta operación descriptiva, se deben buscar propiedades invariantes, es decir, "las propiedades relativamente estables, que son recurrentes en el discurso del soporte a través de temas diferentes". En consecuencia, tomaremos como principales dimensiones de análisis las secciones fijas (algunos artículos particulares de ciertos números se usarán a modo de ejemplo), público meta, uso de recursos gráficos y publicidades de Ciencia Nueva.

Para este estudio se relevaron sus 29 números, publicados desde abril de 1970 hasta diciembre de 1973-enero de 1974. Se accedió a los ejemplares digitalizados en el perfil de la plataforma Issuu de Editorial Ciencia Nueva, donde también se encuentran algunos de los libros publicados por la editorial. Se identificaron más de 400 artículos clasificados según su título, autor, origen del autor (argentino, latinoamericano, otra nacionalidad), sección, tipo de texto (editorial, entrevista, traducción, humor, crónica, etcétera), extensión en páginas, presencia o no de recursos gráficos y de qué tipo, y palabras clave. Por otro lado, para acercarnos al lectorado de Ciencia Nueva, las 104 cartas del lector publicadas en la revista se observaron según el género de su autor o autora, su profesión o institución de pertenencia, su procedencia, y palabras clave. Finalmente, las publicidades identificadas en Ciencia Nueva se analizaron según el anunciante, su origen, la recurrencia del artículo, su tamaño, y su ubicación en la revista.

\section{Resultados}


Ciencia Nueva ha sido calificada como un "milagro editorial" (Borches, 2014) por las condiciones sociohistóricas en las que surgió y por la continuidad que mantuvo a lo largo de cuatro años. En contraposición, otras publicaciones intelectuales de la época se caracterizaban por su efímera vida y no lograban consolidarse luego del entusiasmo inicial de los primeros números. La posibilidad de aparición de Ciencia Nueva en tanto producto gráfico debe leerse en relación con el boom editorial de los años '6o (Faierman, 2017); su orientación como plataforma abierta de discusión sobre ciencia y política científica y tecnológica, en relación con la preocupación de ciertos sectores de poner la temática en la agenda pública. Ambas condiciones dan cuenta de una creciente permeabilidad en las fronteras de los campos editorial, cultural, intelectual y científico de Argentina, y de la voluntad

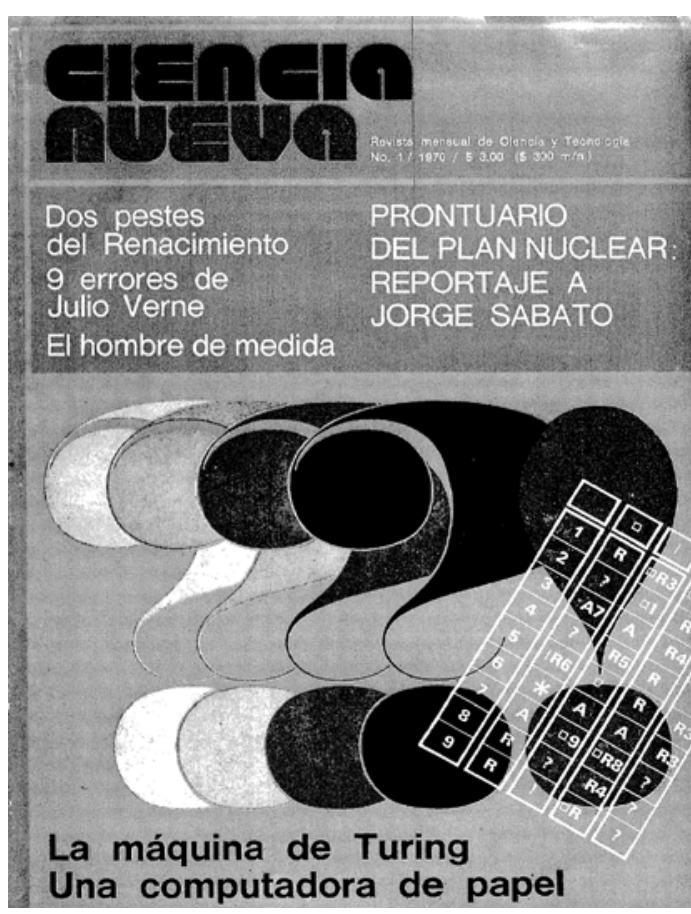

Figura 1: portada del primer ejemplar de

Ciencia Nueva (abril 1970) de referentes de cada uno de estos ámbitos para generar conexiones hasta entonces no exploradas.

Ciencia Nueva tuvo una inmediata y positiva recepción. Además de su clara línea editorial, construyó su identidad como publicación periódica mediante una frecuencia bastante regular y un formato gráfico estable. Estas regularidades son, según Verón (1985), algunos de los elementos invariantes que contribuyen a cimentar el contrato de lectura entre un medio gráfico y su lectorado. Si bien la revista se anunciaba como "mensual", en los hechos alternaba entre una frecuencia mensual y bimensual.

Tapa y contratapa se imprimían a dos colores, mientras que el interior era en blanco y negro. Las páginas se presentaban maquetadas en dos o tres columnas. Cada número contaba con 64 páginas más las tapas, en formato $A_{4}$, es decir, 17 pliegos tamaño $A_{3} \cdot{ }^{7}$ En la parte superior de la tapa figuraba el logotipo de la revista, el número y año del ejemplar, y el precio de venta tanto en pesos moneda nacional como en pesos ley ${ }^{8}$. Debajo de este encabezado se encontraba un recuadro con los títulos más destacados. Finalmente, una ilustración alusiva al artículo principal (cuyo título a veces se superponía sobre la imagen) ocupaba el espacio restante en la tapa (aproximadamente $2 / 3$ de la página). A partir del número 14 el precio de tapa comenzó a figurar solamente en pesos ley, mientras que en la

\footnotetext{
7 El número 19 (octubre 1972) es la única excepción. Tuvo 72 páginas más las tapas, es decir, 19 pliegos. La editorial de ese ejemplar explicaba: "en este número hemos logrado un aporte publicitario que nos permite extendernos otras 8 páginas y así mantener una adecuada proporción de material estrictamente periodístico" (CN\#19, 1972:3). ${ }^{8}$ El Peso Moneda Nacional $(m \$ n)$ fue la moneda de curso legal vigente en la Argentina de 1881 a 1969. Las distintas crisis económicas y devaluaciones de la moneda llevaron a que en el año 1970 entrase en vigencia la Ley 18.188, que sustituyó el peso moneda nacional por el peso Ley (\$). Este fue la moneda vigente de 1970 a 1983. Para que el público se fuese acostumbrado a la conversión, mientras se confeccionaban los nuevos billetes se continuaban emitiendo los valores existentes pero resellados con los nuevos valores.
} 
página 2, dedicada a los datos editoriales y legales de la revista, los precios del ejemplar, de las suscripciones y de los envíos al interior del país seguían indicando los valores en ambas monedas (los envíos al exterior se cobraban en dólares). En la página 2 también figuraban los datos de la Editorial Ciencia Nueva, los distribuidores, la imprenta, y el registro de propiedad intelectual.

El equipo de Ciencia Nueva se fue ampliando con el correr de los años y el crecimiento de la propuesta, pero a grandes rasgos su staff se componía de director(es), asesores científicotécnicos, secretario de redacción, redactores, y diseñadores. Desde el número 1 hasta el número 5, los directores fueron el ingeniero civil Ricardo Ferraro, el físico Ignacio Ikonicoff 9 y el químico Eduardo Mari. Luego estos últimos se apartaron en pos de otros proyectos y la dirección quedó en manos sólo del primero.

La revista tenía corresponsales en distintas ciudades del mundo: Londres, París, Frankfurt, Nueva York, por mencionar algunas, es decir, nodos centrales en el campo científico internacional. A éstas se fueron sumando ciudades latinoamericanas relevantes como nodos científicos regionales: San Pablo, Montevideo o Santiago de Chile. Se desempeñaban en esta función tanto científicos argentinos residentes en el exterior como extranjeros con quienes los miembros de Ciencia Nueva habían establecido contacto en sus actividades académicas, especialmente a partir de estadías en el exterior o visitas de colegas a la Argentina. Con el tiempo Ciencia Nueva también incorporó corresponsales fijos en ciudades argentinas, entre ellas, Córdoba, La Rioja, Mendoza y Rosario. A partir del número 17, y a pedido de los lectores, la revista habilitó el servicio de suscripciones en Uruguay a través de una representante en Montevideo.

Por otra parte, la revista contaba con acuerdos de reproducción y traducción de publicaciones científicas que fueron "modelos de aprendizaje y amigos en el crecimiento" (Ferraro, 2010:45). Entre ellas se destacan New Scientist (inglesa), Science et Avenir, La Recherche (francesas), Sapere (italiana), y Science (estadounidense). También existían acuerdos con las agencias de noticias Associated Press, APN, TASS, CTK, ADN, Agencia DAN, e Icapress; y los servicios culturales de las embajadas de Francia, Gran Bretaña, Italia, Estados Unidos y Japón. Particularmente, a partir del número 11 (julio 1971), Ciencia Nueva estableció una fructífera relación con La Recherche. Esta revista de divulgación científica, fundada en 1946 bajo el nombre de Atomes, aún se publica en formato papel y electrónico. En varios aspectos, La Recherche fue la principal referencia de Ciencia Nueva, especialmente en cuanto a aspiraciones, modelo de publicación y público meta. Como reconoce Ferraro (2010:45), "no inventamos el modelo de publicación que se llamó CN."

Las estrategias de reproducir artículos escritos por determinados autores y tomar ciertas publicaciones extranjeras como referentes no son, al decir de Kreimer (1998), ingenuas, ni incompatibles con la retórica antidependentista de Ciencia Nueva. Además de introducir y difundir corrientes de investigación novedosas o inexistentes en el país, la reproducción de artículos permitía "identificarse [...] con esas corrientes, lo cual sucede en un momento de construcción de un nuevo campo" (Kreimer, 1998:63). Es decir, dado que Ciencia Nueva era una recién llegada, legitimarla en el campo de publicaciones especializadas era una

9 Desaparecido por la última dictadura militar argentina. Ikonikoff y su esposa fueron secuestrados el 25 de junio de 1977 (Departamento de Estado de los Estados Unidos, 1977). Ricardo Ferraro (2010:51) expresa: "Desde que Ignacio Ikonicoff abandonara la codirección no supimos nada de él. Cuando, a comienzos de los '8o, se empezó a aclarar la situación y a disponer de más información, supimos que había sido secuestrado en los años del golpe." 
necesidad. Ciencia Nueva como enunciador se posicionaba de este modo como una publicación nueva, pero de inmediata referencia para aquellos interesados en temas científico-tecnológicos de frontera.

\subsection{Contenidos}

\subsubsection{Secciones fijas}

En un medio gráfico, el ordenamiento de la información es necesario para dar una organización de conjunto a la publicación y para "facilitar el encuentro del lector con sus temas de interés" (Druetta y Saur, 2013:141). Para tal fin, cada número de Ciencia Nueva contaba con un índice en la primera página en donde se listaban las secciones fijas y los artículos publicados, con el nombre del autor cuando correspondiera. Las secciones fijas de Ciencia Nueva eran las siguientes:

\section{a. Editorial}

La editorial es un artículo que no lleva firma, sino que busca representar la opinión del medio como entidad y explicitar la línea editorial. Suele ser redactada por el director o de forma colectiva por el equipo de redacción. Es un escrito que puede tener un tono apelativo, de llamado a la acción. Ciencia Nueva publicaba entre uno y cuatro artículos editoriales de extensión variable en cada número (en total se publicaron 57 ).

A través de las editoriales el equipo de Ciencia Nueva se dirigía al lector, anunciaba eventos, actividades y emprendimientos propios, y realizaba periódicos balances sobre su labor periodística y logros alcanzados.

CIENCIA NUEVA no ha cumplido aún un año de vida, pero la gratificación que paga nuestro esfuerzo hace ya innecesario esperar el convencional cierre de ejercicio [...] el balance es positivo porque CIENCIA NUEVA ha superado la desconfianza inicial de algunos sectores especializados y ha alcanzado, sin restricciones, el apoyo generoso de científicos, técnicos y estudiantes de todas las áreas. (CN\#8, 1971:3)

Desde el 2 de julio ampliaremos nuestros "canales de comunicación": CIENCIA NUEVA estará todos los domingos, a las 19, en Radio Municipal [...] El éxito de nuestra primera Mesa Redonda, la adhesión manifestada por nuestros lectores, nos alentaron a preparar una segunda [...] Estos son algunos resultados de casi cuatro años de trabajo. En cada nuevo número que editamos y en cada ejemplar que se vende se hace realidad aquella fe utópica de publicar CIENCIA NUEVA en la Argentina de hoy. (CN\#17, 1972:3)

La sola publicación de un trabajo no puede significar una toma de posición específica de la revista con relación a la ideología que ese trabajo sustenta [...] En lo que respecta a la posición de la revista, sólo es válido considerar como tal la expresada en las notas editoriales. (CN\#12, 1971:64)

Esta última cita manifiesta cómo la editorial también es el artículo mediante el cual un medio puede tomar distancia de las opiniones vertidas por un determinado colaborador. En efecto, Ciencia Nueva las usaba para aclarar la posición de la revista con respecto a algún artículo que contrariara su línea editorial. Por ejemplo, en el número 5 (octubre de 1970) se publicó "La política científica oficial", una entrevista a Alberto Taquini, secretario en aquel entonces del Consejo Nacional de Ciencia y Técnica (CONACYT, actual CONICET). El formato de la entrevista es pregunta-respuesta, es decir, el periodista se limita a redactar el diálogo respetando el discurso directo de Taquini y sin incurrir en interpretaciones. Esto 
se reserva para la editorial de ese número, "CONACYT, una montaña de papel", donde se critica abiertamente al burocrático funcionamiento de dicha institución.

En las editoriales es donde se percibe con claridad la cercanía ideológica de Ciencia Nueva con el PLACTED. En sintonía con los movimientos de liberación latinoamericanistas de la época, la revista en tanto enunciador construye una imagen propia de oposición a cualquier tipo de autoritarismo e imperialismo, en contra del intervencionismo militar y la injerencia de potencias centrales en los países periféricos, especialmente en la definición de sus políticas públicas de ciencia y técnica. Asimismo, las editoriales de la revista cuestionan duramente el funcionamiento del sistema científico argentino, latinoamericano e internacional. Estos tres niveles se articulan en la crítica a las instituciones y las políticas científicas nacionales (o a la falta de ellas), que no colaboraban a contrarrestar el "cientificismo" y la disociación entre ciencia, industria y sociedad.

Finalmente, tal vez la función más importante de las editoriales de Ciencia Nueva era la de denuncia, crítica y expresión de la postura política de la revista. Además de los reclamos específicamente relativos a las condiciones de la práctica científica, a través de las editoriales se percibe la sensibilidad de la revista para con los conflictos sociales de la época. Las editoriales sientan posición sobre desnutrición infantil, salud pública, educación, crecimiento y planeamiento urbano, ecología, entre otros. Al mismo tiempo, al avanzar los años aumentan las denuncias de persecuciones políticas, detenciones arbitrarias, y atropellos a libertad de expresión.

El año 1973 resulta particularmente conflictivo. La retirada de las tropas estadounidenses de Vietnam fue calificada como "un hito en la historia de la humanidad" en la editorial "Después de Vietnam" (CN\#22, marzo de 1973). Esa editorial se explaya sobre los usos bélicos de la ciencia, la responsabilidad del científico sobre las aplicaciones de sus investigaciones, y el activismo antibélico de intelectuales de renombre internacional.

Además, la editorial "Argentina, 1973" (CN\#22, 1973) celebra las primeras elecciones democráticas y plenamente libres en Argentina desde el derrocamiento de Juan Domingo Perón en $1955^{10}$. La revista hace referencia a la "euforia popular", la "alegría" y "renovadas esperanzas" que trajo el resultado electoral. En el número siguiente, mayo de 1973, la revista describe algunos de los desafíos que
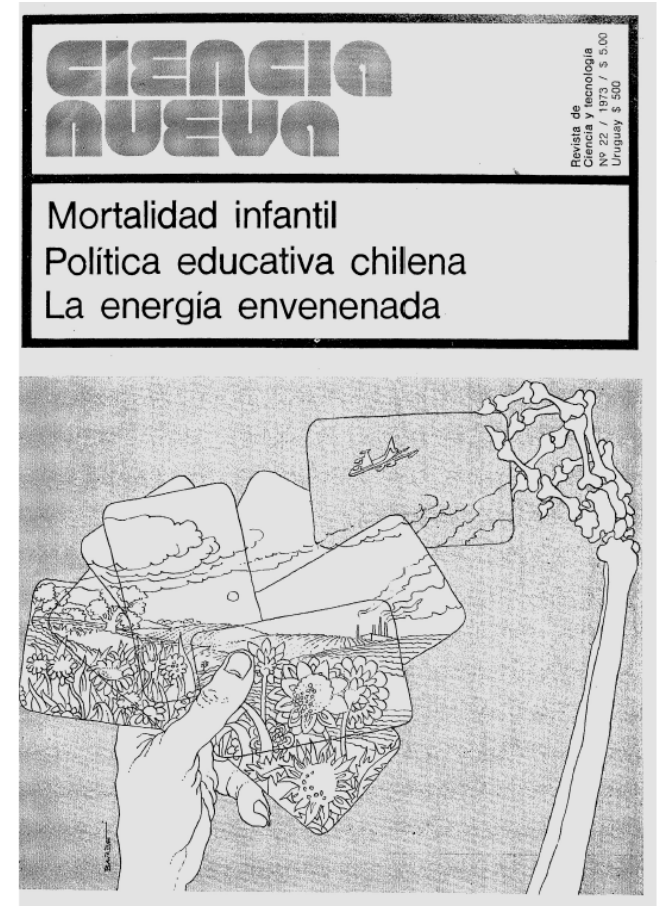

Figura 2: Portada de Ciencia Nueva \#22 (marzo 1973).

\footnotetext{
10 Las elecciones presidenciales de 1973 levantaron la proscripción que regía sobre el peronismo, si bien no se permitió la candidatura del propio Perón.
} 
debían ser encarados en este nuevo período, y hace un llamado a "todos los universitarios, a los científicos, los técnicos, los docentes y los alumnos, a un replanteo profundo y amplio del papel que a cada uno cabe y el que toca uno de los organismos en el que integran sus tareas" (CN\#23, 1973:3). Ciencia Nueva se manifiesta optimista ante la reconstrucción y la sensación de inevitabilidad del cambio social, pero consciente de la dificultad de la tarea. "La ciencia y la técnica han de cumplir un papel clave en la preparación y consecución del proyecto nacional que el gobierno popular deberá realizar para lograr los objetivos de reconstrucción y liberación nacional" (CN\#24, 1973:3).

Para entonces, Ciencia Nueva había comenzado a alinearse con las corrientes de izquierda del peronismo, "en el marco de un Perón en busca de apertura, de ampliar los márgenes de su movimiento [...] al que no le había pasado inadvertido el contexto de época de intensidad y radicalización política de tinte liberacionista" (Faierman, 2017:24). Esta tendencia sólo puede palparse a través de las editoriales, ya que era política del medio no negarse a la publicación de artículos escritos por organizaciones o autores de otras posiciones, si el material era de calidad. De esta manera, opositores al peronismo como el historiador de la ciencia José Babini o el filósofo Mario Bunge continuaron colaborando regularmente con la revista.

Este clima de optimismo se irá enfriando ante hechos acontecidos en Argentina, como la renuncia de Rodolfo Puiggrós al Rectorado de la Universidad de Buenos Aires, a quien Ciencia Nueva consideraba "[...] el primer intelectual de envergadura nacional que se incorporó al peronismo. La política que hizo Puiggrós en la Universidad fue innegablemente anti-imperialista, anti-oligárquica, anti-represiva" (CN\#27, 1973:4). También se denuncia la detención y allanamiento de los domicilios de los doctores Juan José Giambiagi y Amilcar Herrera: "La experiencia histórica muestra que la persecución ideológica y la caza de brujas suele cebarse con los intelectuales. En el momento político que vive el país, esto sería tan inexplicable como catastrófico" (CN\#28, 1973:4). Mirando hacia América Latina, Ciencia Nueva condenaba el golpe militar en Chile: "[...] como científicos argentinos identificados con los ideales de igualdad, justicia y liberación de la Unidad Popular, compartimos el duelo latinoamericano ante la trágica desaparición del presidente Salvador Allende" (CN\#27, 1973:3); e interpretaba la intervención de la Universidad de la República del Uruguay: "Es preciso que conservemos nuestra capacidad de escandalizarnos ante el escarnio y la persecución de que están siendo víctimas [...] numerosos intelectuales uruguayos" (CN\#28, 1973:3).

\section{b. Juegos Matemáticos}

Esta sección fue incluida en la revista desde el inicio y rápidamente se convirtió en una de las más populares y que mayor interacción con los lectores generaban. Estaba a cargo de Manuel Risueño, abogado egresado de la Universidad de Valparaíso, Chile, quien tomó el modelo de los "Mathematical Games" de la revista Scientific American. "Juegos Matemáticos" se dedicaba a las matemáticas recreativas, desarrollando conceptos de álgebra, lógica, geometría y cálculo que eran aplicados a desafíos o acertijos. En cada ejemplar se brindaban las soluciones de los problemas planteados en el anterior. La sección no tenía ubicación fija pero sí una extensión considerable, de entre 3 y 5 páginas, y solía hacer uso de recursos gráficos como tablas, esquemas y figuras, especialmente para el planteo de temas de geometría. Se observa una progresión en la dificultad de los problemas expuestos, así como el desarrollo en serie de temas relacionados. Por ejemplo, el primer artículo de la sección, "Los polióminos", tuvo dos continuaciones, "Los polióminos II" y "Los polióminos III". Es por esto que el autor recurre a recursos retóricos 
apelativos para recuperar conceptos tratados en entregas anteriores, anticipar próximos contenidos, e involucrar y motivar al lector a buscar sus propias soluciones. En ese sentido, se trata de la sección más autorreferencial de la revista. Es característico el uso del "nosotros" inclusivo y de preguntas retóricas: "¿Puede el lector encontrar otra pareja de números amigables?" (CN\#2, 1970:30), "De acuerdo con la insinuación que dejamos hecha en nuestro artículo del primer número de Ciencia Nueva, volveremos hoy a los polióminos..." (CN\#4, 1970:15), "En un número próximo daremos a conocer nuestras soluciones y las que nos lleguen de los lectores" (CN\#13, 1971:45), "Resulta interesante relacionar este problema con el de las paredes sólidas a que nos referimos en el primer artículo de esta serie" (CN\#24, 1973:50).

\section{c. Humor Nuevo}

A partir del número 4 (agosto 1970) la revista comenzó a incluir una página de humor gráfico a cargo de Julio Moreno, médico psiquiatra y dibujante. Al poco tiempo de incorporarse a Ciencia Nueva, Moreno partió a realizar su doctorado en la Universidad de California, pero continuó enviando regular y puntualmente sus colaboraciones a Buenos Aires. Los dibujos eran simples y claros, privilegiando la imagen y los símbolos por sobre el diálogo de los personajes. Inicialmente las viñetas se trataban sobre el trabajo científico, la tergiversación del sentido de las investigaciones, el mal uso de descubrimientos, la aplicación deshonesta de los productos de la ciencia, o las presiones sufridas por los investigadores. Luego fueron apareciendo temas políticos y sociales, como la superficialidad de las experiencias humanas, la soledad, la explotación indiscriminada de la naturaleza, el psicoanálisis, la relación médico-paciente, la discriminación, la segregación, la falta de solidaridad, la policía y las fuerzas armadas, entre otros. 
Además de las viñetas humorísticas, Moreno ilustró algunas portadas de la revista, entre ellas la del número 10 (mayo 1971), de especial relevancia por el punto de inflexión que representó en la trayectoria de la publicación: mostraba un investigador en su laboratorio sosteniendo un balón de precipitado con la bandera estadounidense. El título de portada era "Ideología en la ciencia", y el artículo central de ese número era, precisamente, "Ciencia e ideología", del matemático, epistemólogo y filósofo Gregorio Klimovsky.

Por muchos motivos, se considera el décimo ejemplar como un punto de inflexión en la trayectoria de la revista. En efecto, la publicación del mencionado artículo de Klimovsky inaugura uno de los debates de mayor continuidad a lo largo de la revista, que sería retomado y discutido por otros autores y lectores en diferentes secciones. Klimovsky dividía la actividad científica en tres contextos: de descubrimiento, de justificación, y de aplicación. Sin negar la injerencia de ideologías en el primer y tercer contexto, Klimovsky sostenía que la ciencia como actividad lógica y metodológicamente correcta se podía hallar (solamente) en el contexto de justificación, donde no habría "aspectos ideológicos que afecten la objetividad del conocimiento" (CN\#10, 1971:18). Esta división de la actividad científica, sin

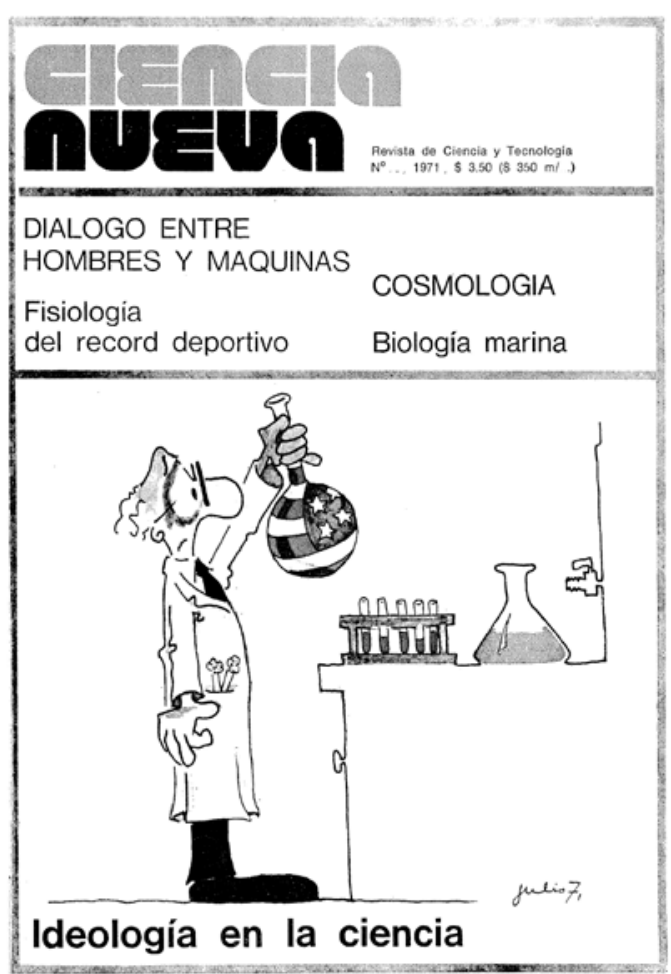

Figura 3: Portada de Ciencia Nueva \#10 (mayo 1971)

cuestionamientos de base a las instituciones o prácticas científicas, suscitó encendidas críticas tanto desde el cuerpo de textos de Ciencia Nueva como desde las cartas del lector, donde los propios autores se respondían unos a otros. Por otro lado, la portada colocaba a Ciencia Nueva en las antípodas de los modelos lineales de desarrollo fomentados por organismos internacionales. La ilustración daba a entender que la política internacional, con los Estados Unidos a la cabeza, había ingresado a los laboratorios y los científicos ya no podrían ignorar la situación. El propio Ricardo Ferraro reconoce que la intención de la revista era "ingresar en el campo del debate político" (2010:16). Observamos en esto un cambio en el contrato de lectura propuesto inicialmente. Si bien desde sus comienzos Ciencia Nueva se constituyó como un enunciador crítico al orden social y científico, tematizar la "Ideología en la ciencia" como nota de tapa da cuenta de un "salto cualitativo en cuanto a la explicitación de un posicionamiento político" (Faierman, 2017:23). Este cambio fue bien recibido por el lectorado: "provocó una lluvia de cartas, llamados telefónicos y visitas a la redacción (en 1971 no existía Internet) de decenas de lectores que repetían: '¡Por fin! ¿Por qué esperaron tanto?'"' (Ferraro, 2010:16).

\section{d. Metegol}

En el número 5 se incluyó por primera vez el recuadro de acertijos lógicos "Metegol", "pequeños problemas, al alcance de todos, que pocos resolvían" (Ferraro, 2010:16). Las 
soluciones se brindaban en el número siguiente. Al igual que la sección "Juegos Matemáticos", se volvió muy popular.

\section{e. Novedades de Ciencia y Tecnología / El Filtro de las Noticias}

Dentro de una revista dedicada a la CPC, esta sección es la que más claramente se recorta como periodismo científico propiamente dicho. "Novedades de Ciencia y Tecnología" era el paneo informativo que la revista realizaba recogiendo las últimas noticias y avances en diversas áreas de las ciencias. Consistía en pequeñas reseñas de aquellos experimentos o artículos publicados en revistas científicas prestigiosas que daban cuenta de estudios de frontera y tecnologías de punta. Por esto, la sección recogía principalmente noticias científicas provenientes de los centros de mayor importancia mundial: Estados Unidos, Europa, la Unión Soviética y Japón, aunque también se incluían noticias de orden nacional o regional, o que involucraran a científicos argentinos o latinoamericanos trabajando en el exterior.

La sección no tenía ubicación fija en la revista. Constaba de alrededor de diez pequeñas columnas que ocupaban en total entre cuatro y seis páginas, con imágenes incluidas. Cabe destacar que en los primeros ejemplares de Ciencia Nueva esta sección tenía una extensión mayor. Posiblemente, con la creciente capacidad de la revista de generar contenido propio, además de las exigencias de reservar más espacios para publicidad, esta sección haya debido ceder algunas de sus páginas. En efecto, en el número 8 (marzo 1971) aparece la sección "El Filtro de las Noticias", con el mismo concepto que "Novedades..." pero de sólo una página de extensión. Desde entonces, de acuerdo con las necesidades de paginación y diagramación, estas secciones se publicarían de manera alternada. Es decir, "El Filtro..." no vino a reemplazar a "Novedades...", sino que actuó como su versión condensada cuando la abundancia del resto de material lo exigía.

\section{f. Libros Nuevos / Comentarios de Libros}

Ambas secciones se dedicaban a reseñar libros académicos recientemente publicados y a anticipar otros de inminente aparición. "Libros Nuevos" se limitaba a transcribir los índices o brindaba un rápido sumario del contenido del libro, mientras que "Comentarios..." consistía en revisiones críticas y reflexiones valorativas a cargo de especialistas en cada temática. En el número 27 (octubre 1973) las dos secciones se combinaron en una sola llamada simplemente "Libros". La revista anunciaba:

En este número las habituales secciones Comentarios de Libros y Libros Nuevos se funden en una sola. Asimismo cambia la modalidad en la presentación del comentario y en la ficha técnica. El cambio es más que formal: también el criterio de selección se especializa y adopta un presupuesto político del que hasta ahora carecía, a pesar de estar definido en casi todo el resto de la revista. Alcanzar esta posibilidad no es fácil para una publicación de recursos humanos y económicos limitados. Por eso no lo hicimos antes; ahora podemos hacerlo... y esperamos que nos dure. (CN\#27, 1973:60)

En estas secciones figuraron obras de gran influencia hoy consideradas clásicas, como "Las estructuras elementales del parentesco", de Claude Lévi-Strauss; "¿Extensión o comunicación? La concientización en el medio rural", de Paulo Freire; "El carácter de las leyes físicas", de Richard Feyman; "La investigación científica, su ética y su filosofía", de Mario Bunge, o las obras completas de Bertrand Russell. La creciente politización de la revista puede palparse en esta sección en tanto y en cuanto en los primeros números las reseñas de libros eran principalmente textos sobre ciencias exactas o historia de la ciencia, 
mientras que más adelante se comienzan a incluir obras de ciencias políticas, sociología, etc.

Asimismo, se hace mención de la aparición y se comentan los que hoy consideramos dos de los libros fundantes del PLACTED: "Ciencia, política y cientificismo", de Oscar Varsavsky; "Ciencia y política en América Latina", de Amílcar Herrera; así como obras de científicos e intelectuales relacionados con esta corriente y colaboradores habituales de Ciencia Nueva, tales como José Babini, Félix Cernuschi, Oscar Maggiolo, o Darcy Ribeiro, por mencionar algunos. Cada uno de los autores identificados dentro de esta corriente tenía sus propios espacios formales de publicación, sobre todo aquellos que estaban insertos en sus respectivos campos científico-académicos. Sus formulaciones teóricas y conceptuales sobre ciencia, tecnología, desarrollo y sociedad usualmente terminaron adoptando el formato libro. Ciencia Nueva cumplía otra función: era el terreno del diálogo, el debate, la polémica, y muchas veces la confrontación directa. La periodicidad mensual de la revista permitía un seguimiento más o menos cercano de cuestiones de actualidad, mientras que daba tiempo a la reflexión para un posterior intercambio público de posturas. Es decir, el ejercicio de escritura para la revista generaba textos de alto nivel teórico, los cuales pasaban a formar parte del acervo conceptual del PLACTED. Baste señalar que el libro "El pensamiento latinoamericano en la problemática ciencia-tecnología-desarrollodependencia", compilado por Jorge Sábato en 1975, recoge varios de los debates y entrevistas publicados en Ciencia Nueva, a pesar de que ésta hubiera dejado de existir en 1974. Si se toman los escritos del PLACTED como el primer movimiento analítico latinoamericano relativo a estudios sociales de la ciencia y la tecnología (Vessuri, 1987; Kreimer, 2007; Jiménez Becerra, 2010; Feld, 2011) pese a que no hayan constituido una escuela teórica propiamente dicha ${ }^{11}$, la importancia de Ciencia Nueva como espacio de encuentro e instancia de publicación es difícil de soslayar.

\section{g. Cursos y Reuniones Científicas}

Esta sección, concebida como información de servicio para la comunidad científica, listaba los congresos, conferencias, capacitaciones, jornadas o simposios próximos a realizarse. Se incluían eventos locales, nacionales y regionales, organizados por universidades, centros de investigación o asociaciones profesionales. Por lo general se ofrecía el programa de la reunión y se brindaba información sobre la forma de inscripción, lugar y fecha. Esta sección se ubicaba en las páginas finales de la revista.

\subsubsection{Uso de recursos gráficos}

Ciencia Nueva utilizaba una variedad de recursos gráficos en la mayoría de sus artículos, si bien mostraba una distribución irregular del texto, las imágenes y los espacios en blanco. El uso de recursos gráficos no se condice con la extensión de los artículos: hay textos de hasta nueve páginas de extensión que no presentan ningún elemento gráfico. El resto (de entre una y quince páginas) incluye una variedad de recursos gráficos. La fuente o autor del elemento gráfico se indicaba intermitentemente, excepto en las ilustraciones originales de

\footnotetext{
${ }^{11}$ Según diversos autores (Kreimer, 2007; Casas Guerrero, 2004; Hurtado, 2011), no resultaría apropiado hablar del PLACTED como una "escuela" ya que sus principales referentes no provinieron de espacios académicos tradicionales, no establecieron líneas de continuidad en cuanto a la formación de nuevas generaciones de investigadores, y no necesariamente compartían orientaciones teóricas ni metodológicas. Pero los libros clásicos de la época y los debates dados en Ciencia Nueva definitivamente constituyen el primer movimiento hacia el establecimiento de un área de reflexión en CTS, que en décadas siguientes sí se conformaría como un campo académico delimitado.
} 
dibujantes y artistas, que sí llevaban firma siempre, y en los artículos traducidos y reproducidos de medios extranjeros. Esto hace pensar que los convenios de reproducción de textos incluían también permisos de reproducción de los recursos gráficos.

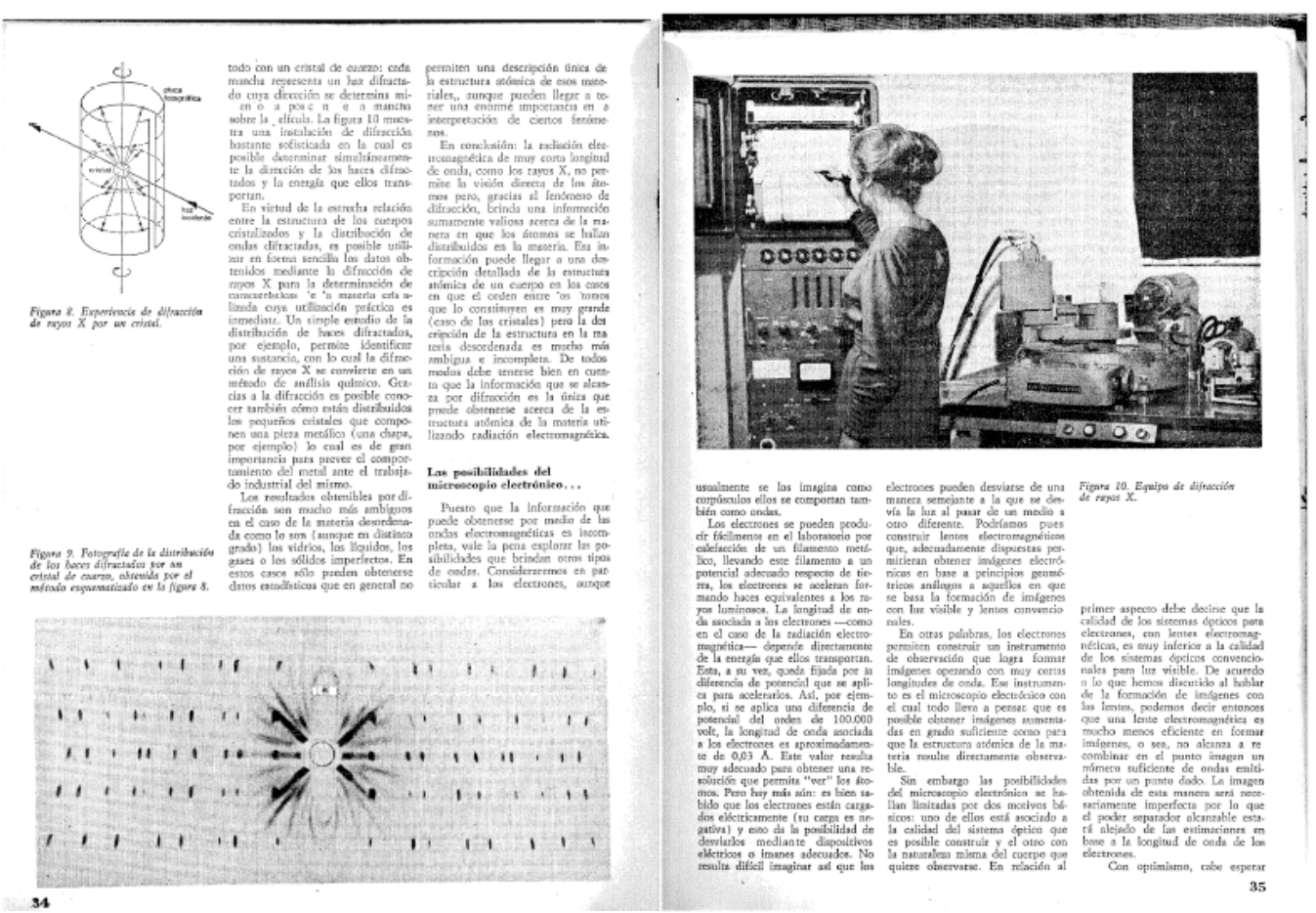

Figura 4: Páginas 34 y 35 de Ciencia Nueva \#8 (marzo 1971). El artículo "¿Podemos ver los átomos?" exhibe los recursos gráficos más usados por la revista: un diagrama (arriba a la izquierda), una fotografía de laboratorio (abajo a la izquierda), y una fotografía que muestra el equipamiento en uso (arriba a la derecha).

En los inicios de la revista primaba el uso de recursos gráficos usualmente empleados en la escritura científica: esquemas, planos, gráficos, tablas, etc. También había fotografías (en especial de obras de ingeniería, instalaciones, laboratorios y equipamientos) e imágenes generadas durante experimentos (por ejemplo, células y tejidos orgánicos vistos a través de microscopios, imágenes astronómicas tomadas por distintas clases de telescopios, etc.). La mayoría estos elementos se acompañaba de epígrafes explicativos numerados sucesivamente como "Figura 1, "Figura 2", lo cual también remite a una forma típica del artículo científico. Además, las entrevistas o perfiles se acompañaban, en la mayoría de los casos, con una fotografía del personaje (por lo general en primer plano). Todas estas imágenes cumplían una función referencial, es decir, se colocaban para complementar o reforzar el contenido verbal de los artículos, cumpliendo una función informativa por sí mismas. En textos de divulgación científica, las imágenes e ilustraciones son clave para graficar y facilitar la comprensión de conceptos abstractos o difíciles de visualizar dado que aún no forman parte del acervo común de conocimiento compartido a nivel social. En términos de contrato de lectura, "las imágenes son uno de los lugares privilegiados donde éste se constituye, donde el enunciador teje el nexo con su lector, donde al destinatario se le propone una cierta mirada sobre el mundo" (Verón, 1985:11). Podemos decir, entonces, que inicialmente la revista utilizaba los recursos gráficos para constituirse como un 
enunciador objetivo e impersonal: las imágenes que remiten a trabajos científicos reafirman la exactitud del conocimiento expresado por escrito.

Paulatinamente, la revista fue incorporando artistas al equipo. La sección "Diseño" se especializó, a partir del número 5 (octubre 1970) en Ilustración/Dibujo, Diseño gráfico y Humor. Asimismo, las temáticas tratadas en los textos comenzaron a incluir más debates sobre política científica, actualidad nacional, y ciencias sociales, temas que ofrecen menos posibilidades de ilustración referencial. Correlativamente, aumentan las ilustraciones artísticas, caricaturas, viñetas humorísticas o satíricas en función ornamental, aunque no puede decirse que carezcan de función referencial. Asimismo, las entrevistas y perfiles comienzan a alternar entre fotografías y caricaturas, en particular en las secciones temáticas especiales del estilo "Mesa Redonda", que reunían aportes de varios autores sobre un mismo tema. Al respecto, Verón (1985) observa que, en todo dibujo o ilustración, a diferencia de la foto de prensa, el enunciador se hace más presente, ya que explicita su intención de querer transmitir un significado particular a través de la imagen. Cabe señalar que hasta el número 10 las portadas habían consistido en fotografías o diagramas científicos. Posteriormente comienzan a predominar las ilustraciones originales. Se destacan las portadas de los números 16-21, ilustradas por los artistas Hermenegildo Sábat, Ernesto Deira, Luis Felipe Noé, Oscar Smoje, Lorenzo Amengual y Rómulo Macció, quienes cedieron sus obras para mostrar que "ciencia, tecnología, creación estética, son partes de una tarea común y pueden y deben integrarse cuando tienen un mismo sentido" (CN\#16, 1972:2). La portada del ejemplar 22 (marzo 1973) fue ilustrada por el dibujante francés Barbe, quien trabajaba como ilustrador en La Recherche. Puede decirse, entonces, que el uso de recursos gráficos fue parte de los cambios que el contrato de lectura de la
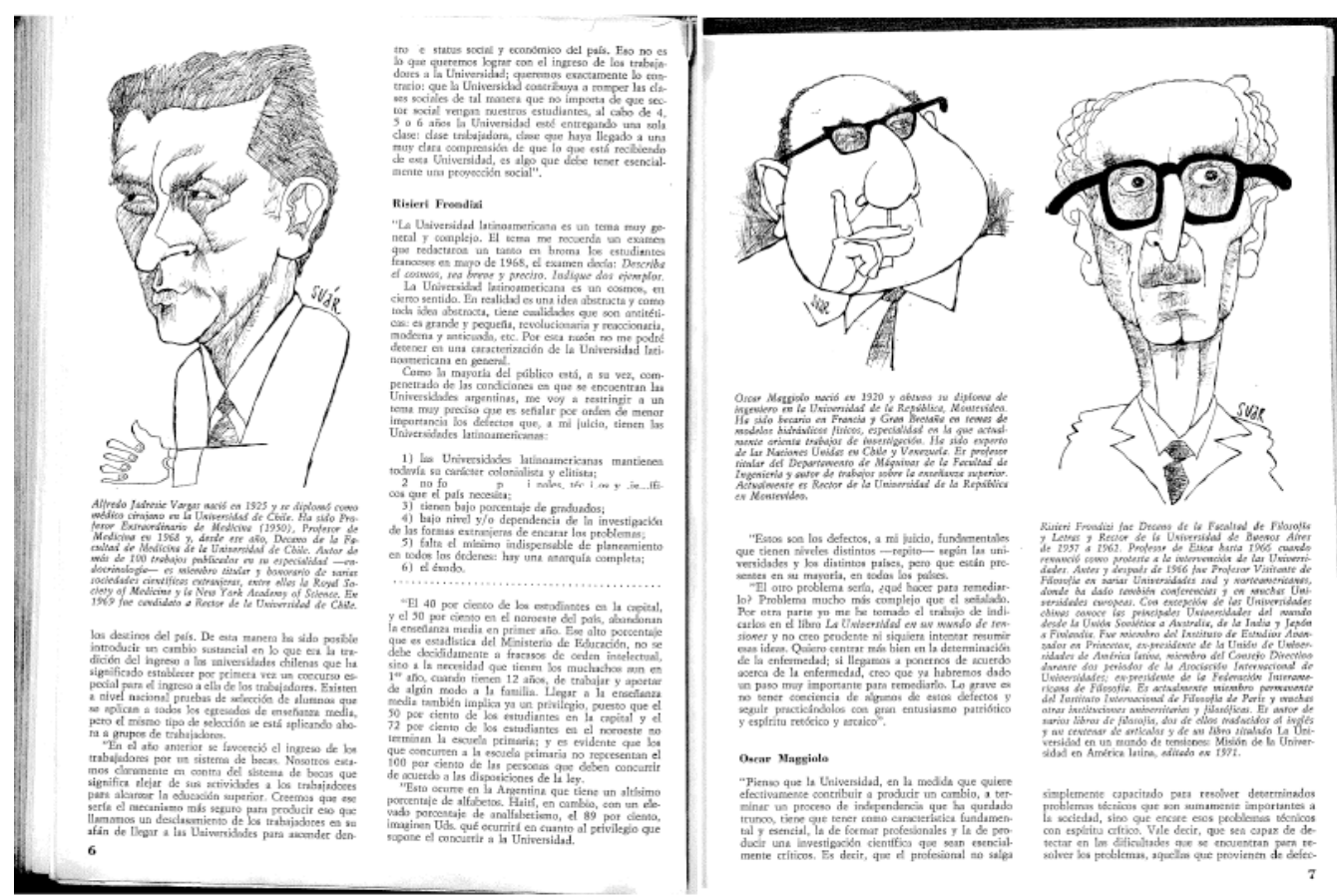

Figura 5: Páginas 6 y 7 de Ciencia Nueva \#19 (octubre 1972). El artículo "La universidad en América Latina" contiene caricaturas de sus autores. En la figura, de izquierda a derecha, Alfredo Jadresic Vargas, Oscar Maggiolo y Risieri Frondizi. 
publicación fue experimentando. Si bien en los artículos netamente de divulgación se mantuvo el uso de recursos gráficos extraídos del ámbito científico, la profusión de textos de orden político fue acompañada por una mayor cantidad de ilustraciones originales de artistas o montajes. Con estas estrategias, el enunciador buscaba erigirse como cómplice del enunciatario, a quien comenzó a interpelar de forma más directa desde lo discursivo y desde lo gráfico.

\subsubsection{Publicidad y financiación}

A partir del segundo ejemplar, Ciencia Nueva comenzó a incluir publicidad para poder sostenerse. Los ingresos por suscripciones llegaron a cubrir sólo el 15\% de los costos (CN\#25, 1973), mientras que "la venta de la revista no cubre los gastos de producción de cada número [...] la comisión por la distribución y venta insume el 50\% del valor de tapa de los ejemplares vendidos" (CN\#3, 1970:63). Las principales ventas directas se daban en los kioscos de las estaciones del subterráneo en la ciudad de Buenos Aires, en universidades (sobre todo en los centros de estudiantes), y en algunas librerías especializadas (Ferraro, 2010).

A lo largo de la existencia de Ciencia Nueva identificamos 59 anunciantes diferentes. 43 son de origen argentino, 15 de origen extranjero, y en un caso no se pudo determinar. En total, 30 (el 51\%) eran anunciantes regulares, es decir, publicaron en la revista dos veces o más. De éstos, 23 (el 77\%) eran de origen argentino, mientras que 6 (el 20\%) eran extranjeros. Esto, sumado a la diversificación de anunciantes con el correr de los números, da cuenta de una consolidación de la revista, y de un interés en apelar al lectorado que se estaba construyendo. Dicha construcción demuestra también una creciente confianza en la publicación como medio gráfico y espacio publicitario, que no perdía oportunidad de agradecer "a las empresas que, rompiendo arraigadas costumbres, apoyaron económicamente nuestro trabajo desde el principio, así como esperamos esa ayuda de muchas otras empresas cuyo trabajo está relacionado con la ciencia y la tecnología" (CN\#8, 1971:3).

En su mayoría, las publicidades provenían de otras publicaciones científicas o culturales ${ }^{12}$, editoriales (Siglo XXI, Centro Editor de América Latina), empresas nacionales de base tecnológica (Fate, Techint, Rigolleau, Acindar, etc.) o ramas locales de empresas extranjeras (BGH, Phillips, Hewlett-Packard, Chrysler, etc.). Si bien esto último parecería contrario a la línea editorial de Ciencia Nueva, el equipo defendió la decisión (y la necesidad) de incluir publicidad "siempre que ello no afecte la calidad del material o la independencia de la revista" (CN\#3, 1970:63). Una medida para mantener esa autonomía fue no imprimir publicidades políticas o de instituciones públicas estatales. La misma medida había sido tomada por La Recherche desde su fundación. Por otra parte, la revista sí publicó solicitadas, manifiestos o denuncias de diversas organizaciones político-partidarias y asociaciones profesionales.

El tono general de las publicidades valoraba positivamente las posibilidades de desarrollo tecnológico en Argentina y hacía énfasis en la generación o fabricación de tecnología en y

\footnotetext{
${ }^{12}$ Ciencia Nueva compartía personal de diseño, diagramación e impresión y algunas instalaciones con las revistas literarias Los Libros y Crisis. Si bien el objetivo inmediato era reducir costos de producción, esta circulación y cercanía con intelectuales argentinos y latinoamericanos da cuenta de la disposición de quienes hacían Ciencia Nueva de atender en un sentido amplio a los debates culturales de la época, que excedían los límites de la mera divulgación científica.
} 
para el país. En muchos casos se explicitaba el referente "internacional" como vara con la que medir el nivel alcanzado en el ámbito local. Asimismo, se observa una exaltación de la tecnología como equivalente de modernización y avance. Las publicidades ofrecían productos y servicios para usos industriales o empresariales, para profesionales relacionados con la ciencia y técnica, y también para el uso doméstico cotidiano.

Las publicidades de firmas locales tendían a buscar demostrar su trayectoria y capacidad: "Tecnología argentina a nivel internacional" (Nicoli-Salgado SA), "No todos se animan a intentar cosas, nosotros sí. Y pudimos todo lo que pretendíamos" (Holimar), "Cuando los éxitos de una empresa son tan constantes, es porque su gente sabe lo que hace" (Alpargatas). Hay un equilibrio entre, por un lado, la referencia a la experiencia, lo ya comprobado, el caso probado de éxito; y por otro, a la novedad, la innovación, la generación de confianza en el nuevo producto o servicio brindado por una empresa nacional que se buscaba insertar en el mercado. Las publicidades de empresas argentinas tenían que lidiar con una doble barrera: la posible reticencia del consumidor a incorporar nuevas tecnologías, y el "complejo de inferioridad con respecto a la capacidad extranjera y a los sectores tradicionales de producción" (Herrera, 2015 [1970]:79).

Por otro lado, el discurso publicitario de las grandes empresas multinacionales apelaba al conocimiento y reconocimiento de la marca, o a su envergadura: "Un acondicionador de confianza... compre la mayor experiencia en aire acondicionado" (Fedders BGH), "HewlettPackard dispone de una organización de ventas, servicio y asesoramiento en 172 ciudades de 65 países" (Hewlett-Packard), "Esta preocupación constante de Siemens por mejorar productos que ya son líderes en el mercado mundial..." (Siemens). Estas corporaciones ya contaban con un importante capital simbólico y por lo tanto sus publicidades buscaban enfatizarlo, especialmente aquellas que apuntaban a introducir nuevas tecnologías (ya

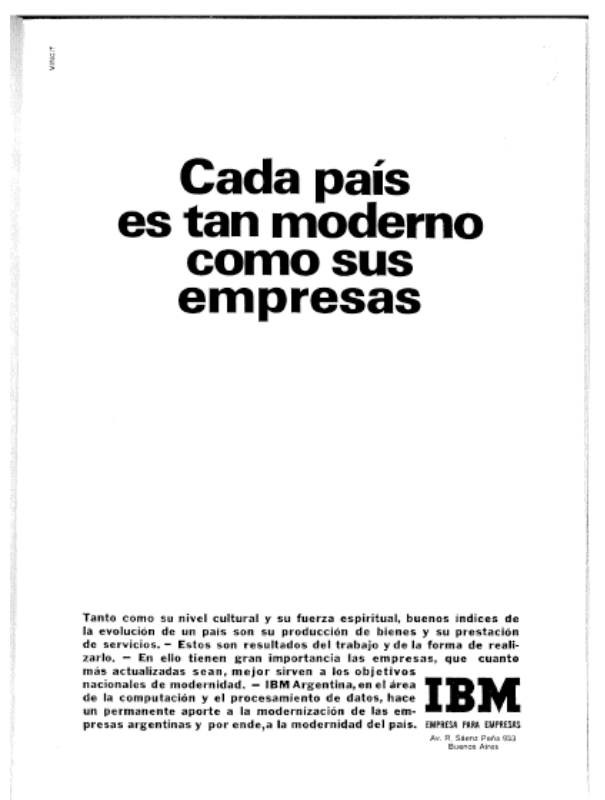

Figura 6: Publicidad de IBM Argentina, página entera impar (CN\#12, septiembre 1971)

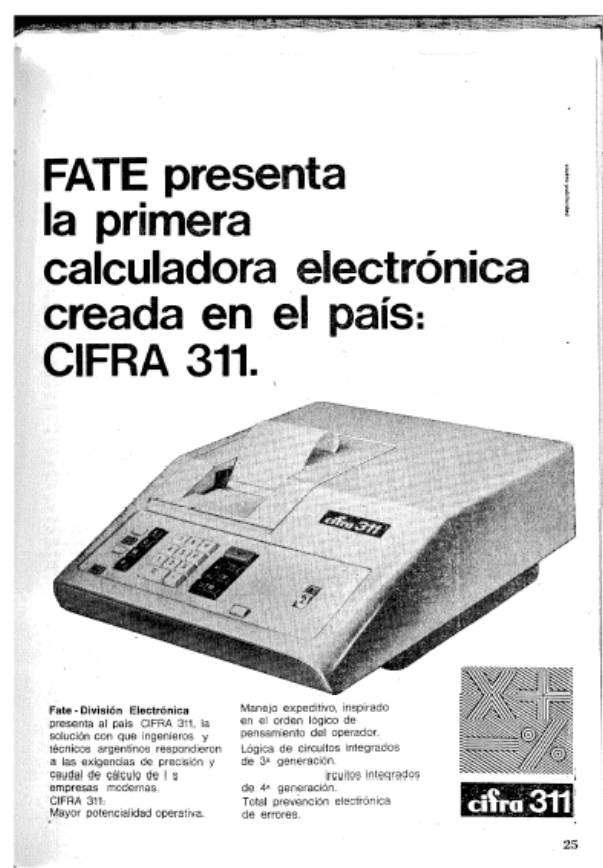

Figura 7: Publicidad de FateDivisión Electrónica, página entera impar (CN\#9, abril 1971)

presentes en los países centrales) al uso cotidiano. 
Los espacios publicitarios se distribuían según la maquetación de la página (a dos o tres columnas). Así, los tamaños iban desde una página completa a media página, un tercio, un cuarto, o un sexto (vertical u horizontal). En Ciencia Nueva se observa una casi nula movilidad entre tamaños por parte de cada anunciante a lo largo del tiempo: quien contrataba un anuncio mantenía sus características ${ }^{13}$. El mecanismo de vender un aviso publicitario por una cierta cantidad de números es habitual en las publicaciones periódicas estables, ya que facilita la diagramación y garantiza un ingreso fijo al tiempo que permite reducir el costo para el anunciante.

En total, un $43 \%$ de los avisos ocupaban una página entera, mientras que un $38 \%$ consistían en anuncios a media página. El 19\% restante se dividía en avisos menores de tercios o sextos de página. Esta preferencia por las fracciones más grandes (página entera o media página) puede emanar de los propios anunciantes, pero también pudo ser una política de la revista. Al diagramar unos pocos avisos a página completa, se tiene más control sobre su distribución y efecto sobre la estética de la publicación que si fueran muchos pequeños avisos de diseño variable. Esto también da cuenta de los recursos que las diferentes empresas $u$ organizaciones disponían para invertir en publicidad. Sólo el $29 \%$ de los anunciantes argentinos publicaron avisos a página entera, contra el $81 \%$ de los anunciantes identificados como extranjeros. Entre los anunciantes argentinos se observa una mayor tendencia a publicar anuncios recurrentes, pero de menor tamaño.

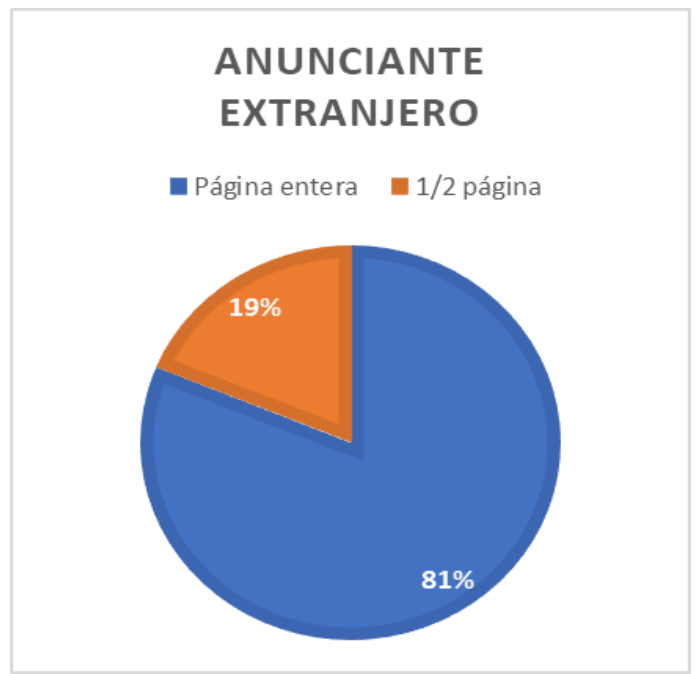

Gráfico 1: distribución porcentual de anuncios por tamaño en anunciantes extranjeros. Elaboración propia.

\section{ANUNCIANTE NACIONAL}
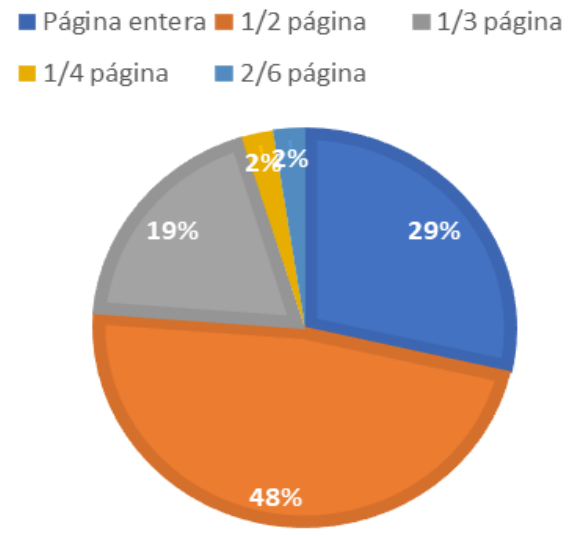

Gráfico 2: distribución porcentual de anuncios por tamaño en anunciantes nacionales. Elaboración propia.

Otro costo asociado con la publicidad gráfica es la ubicación del anuncio. En todo producto gráfico, los espacios más caros son la portada y la contraportada. Le siguen en costo la

${ }_{13}$ Sólo Rigolleau, ABC Electrónica SRL y SEGBA publicaron avisos de diferentes tamaños, para publicitar distintos productos. Por otra parte, Fedders-BGH, SEGBA y EUDEBA fueron los únicos anunciantes que publicitaron en diferentes ubicaciones. En consecuencia, si bien el total neto de anunciantes es 59, para los gráficos de Tamaño del Anuncio y Página de Publicación estos anunciantes se computaron dos veces, elevando el total considerado en estas categorías a 64 . 
retiración de portada y contraportada ${ }^{14}$. Al interior de la publicación, publicitar en página impar es más caro que en par. En Ciencia Nueva, portada y contraportada siempre fueron espacios libres de publicidad. La contraportada en particular atendía a la necesidad de promoción de la propia revista.

Entre los anunciantes, es clara la tendencia a publicar en páginas impares: el $67 \%$ de las publicidades se ubican en estas páginas. Esto se debe a que, en la tradición occidental, las páginas se pasan de derecha a izquierda, con el pliegue siempre a la izquierda del lector. Además, la vista durante la lectura se desplaza sobre el texto de izquierda a derecha y de arriba abajo. Por lo tanto, los elementos que se ubiquen del lado derecho del lector, esto es, en páginas impares, son donde primero cae la mirada, generan más impacto visual y son más recordados. Un $25 \%$ de los anuncios se encuentra en las más económicas páginas pares, mientras que las costosas retiraciones de portada y contraportada suman solo el $8 \%$ de los anuncios.

Al distinguir entre anunciantes argentinos y extranjeros, puede nuevamente inferirse una diferencia en recursos económicos. Los anunciantes extranjeros prácticamente no publican en páginas pares, la mayoría privilegia las páginas impares, y un anunciante extranjero es el único caso de publicidad en retiración de portada. Los anunciantes argentinos, si bien también recurren a la página impar como primera opción, incorporan en mayor medida la publicación en página par como alternativa.

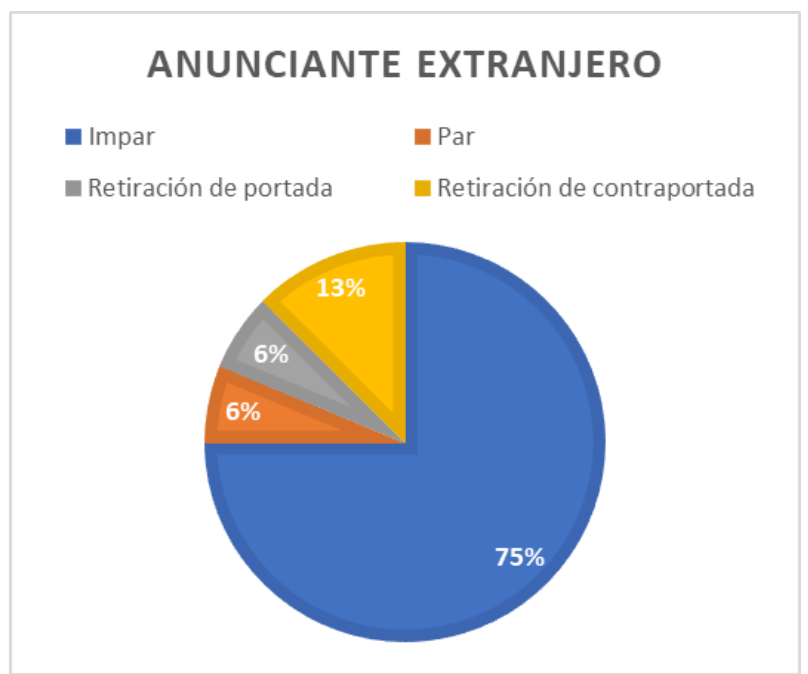

Gráfico 3: distribución porcentual de anuncios por página de publicación en anunciantes extranjeros. Elaboración propia.

\section{ANUNCIANTE NACIONAL}

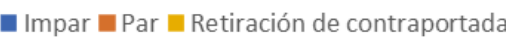

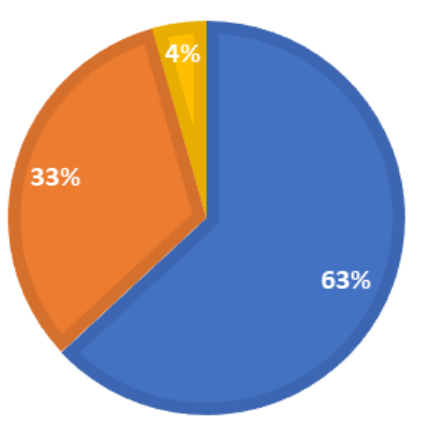

Gráfico 4: distribución porcentual de anuncios por página de publicación en anunciantes nacionales.

En definitiva, como en todo producto gráfico, la publicidad fue el principal recurso económico y una necesidad ineludible para Ciencia Nueva. "En el sistema en que vivimos, la supervivencia de todo medio de comunicación se apoya ineludiblemente en la publicidad

\footnotetext{
${ }^{14}$ La portada y la contraportada forman la cara externa del pliego de portada. La cara interna se compone por la retiración de portada (el anverso de la portada, página que antecede al cuerpo interno de la publicación) y la retiración de contraportada (el anverso de la contraportada, la última página interna de la publicación) (Druetta y Saur, 2003).
} 
comercial" (CN\#8, 1971:3). Más allá de que "su publicación no es una aventura con objetivos comerciales, sino un acto de fe, de militancia" (CN\#19, 1972:5), la revista no ocultaba su esfuerzo en conseguir anunciantes.

\subsection{Públicos}

Todo producto de comunicación se concibe con un destinatario en mente. Esta previsión influye de forma decisiva en las características que adquirirá la producción final. Especialmente en textos de CPC, la anticipación de las competencias que posee el lector meta determinará el tono y complejidad del escrito. Además, el planteo de un contrato de lectura implica anticipar qué clase de lector adherirá al mismo.

Puesto que todo diagnóstico hecho a priori debe confrontarse con la realidad y toda publicación debe conocer a sus lectores reales más allá de definiciones in fabula, en el número 15 (marzo 1972) Ciencia Nueva anunció que, habiendo cumplido tres años de circulación, realizaría una encuesta al público para medir satisfacción, opiniones, o críticas. En el número 20 (noviembre 1972) se publicaron las conclusiones.

La revista se distribuye entre un público cuyas edades oscilan entre los veinte y los cuarenta y cinco años, con preeminencia de los jóvenes de veinte a veinticinco. En su mayoría, son profesionales, profesores universitarios y estudiantes adelantados, de los cuales el porcentaje más alto pertenece al área de las Ciencias Exactas principalmente Ingeniería, Química, Física y Matemática, aunque existe también un sector perteneciente a las Ciencias Biológicas que incluye médicos y estudiantes de Medicina y Biología. (CN\#20, 1972:4)

Este público de Ciencia Nueva puede ser caracterizado como altamente reactivo (Druetta y Saur, 2003) dadas las repercusiones que causaba cada número de la revista, y la ampliación de iniciativas de CPC que la revista motorizó (mesas redondas de debate con alta asistencia, una exitosa colección de libros derivados de la Editorial Ciencia Nueva, la emisión de micros radiales). El lectorado de Ciencia Nueva no sólo acogió con entusiasmo la propuesta, sino que se involucró y se manifestaba vivamente sobre las discusiones planteadas. Puede decirse que el objetivo inicial de la revista se cumplió con creces, ya que en la editorial del primer ejemplar el equipo manifestaba que las páginas de Ciencia Nueva

no son sólo nuestras, del grupo de autores y editores que hoy la iniciamos, pertenecen a todos aquellos que tengan algo que decir sobre el tema. Su éxito o su fracaso depende en realidad, de este diálogo, de esto que solicitamos como colaboración y que se debe, como toda la revista, a la presente generación de argentinos. (CN\#1, 1970:4)

Este llamado a la interacción se sostendría principalmente a través de la sección Correo del Lector, iniciada en el número 2 de Ciencia Nueva. Quienes accedieron al primer ejemplar aceptaron la "invitación formal al diálogo sobre la base de un interés común: la búsqueda de la verdad y la prevalencia de la razón como premisas de toda tarea que sirva al hombre, que sirva a nuestros pueblos" (CN\#1, 1970:62). En los meses subsiguientes la revista publicó no menos de tres cartas de lectores por ejemplar, de extensión muy variable (de un párrafo a una página completa). En total, 104 cartas se publicarían de 1970 a 1974. Las primeras celebran la aparición de Ciencia Nueva y constatan el vacío en publicaciones de este tipo en español, lo que confirma el diagnóstico realizado por el equipo editorial en el momento de planificación de la revista. 


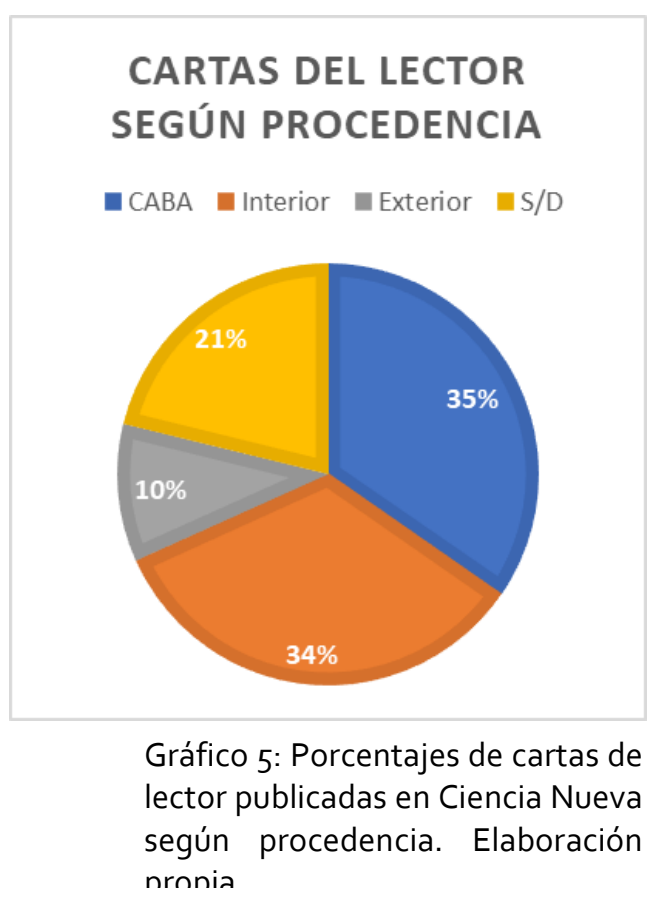

Las cartas del lector sirven, en primera instancia, para analizar el alcance geográfico de Ciencia Nueva. Cabe aclarar que las cartas publicadas responden a un criterio de selección por parte de la revista, por lo que no se puede dar cuenta de las estadísticas del total de cartas recibidas. Además, un alto porcentaje de las cartas no explicitan la ubicación del autor, pero aquellas que sí lo hacen (un total de 82 ) son indicadoras de ciertas tendencias.

Puede observarse que la Ciudad Autónoma de Buenos Aires (CABA) aporta casi el mismo porcentaje al total de cartas que todas las demás provincias argentinas combinadas. Es esperable que una revista lanzada e impresa en Buenos Aires tuviera más lectores en esa ciudad. Es igualmente previsible que los lectores de CABA fueran los más involucrados con la propuesta de la revista, puesto que las actividades paralelas generadas por Ciencia Nueva como las conferencias y mesas debate o los micros radiales se realizaban allí. Esto no impide observar la amplia distribución de la revista por toda la Argentina, incluso con la escasa publicidad que rodeaba la aparición de cada ejemplar. Las 35 cartas firmadas desde el interior provienen de 9 provincias diferentes. Nuevamente, la provincia de Buenos Aires (incluyendo los partidos del conurbano bonaerense y la ciudad de La Plata) presentan la mayor parte de las cartas del lector.

Finalmente, las cartas provenientes del extranjero son en su mayoría de Montevideo, Uruguay. Esto probablemente se debiera a la cercanía entre las comunidades científicas uruguaya (mayoritariamente asociadas a la Universidad de la República [UDELAR]) y argentina. Dentro de la perspectiva latinoamericana de Ciencia Nueva, Uruguay ocupaba un lugar importante. Diversos autores uruguayos escribieron para Ciencia Nueva, incluyendo el Rector de la UDELAR (en dos períodos consecutivos entre 1966 y 1972) Oscar Maggiolo. Por otra parte, cabe recordar que la revista había implementado un servicio de suscripciones en Uruguay y en pesos uruguayos a mediados de 1972. Esto sin duda facilitó el acceso a la revista por parte de los lectores del país vecino, quienes hasta el momento debían adquirirla en Buenos Aires o abonar envíos en dólares.

Otro aspecto a considerar en la descripción del lectorado de Ciencia Nueva es su nivel socioeducativo y profesional. Como se desarrolló al inicio de esta sección, todo texto debe prever las competencias de su lector para decodificarlo. Dice Eliseo Verón (1993) que todo texto carga las huellas de sus condiciones de producción, las cuales influirán en las condiciones de reconocimiento. Desde el polo de la producción de los textos, la revista no logra romper del todo con el estilo del artículo científico. Más allá de su voluntad de apertura y perspectiva crítica hacia el establishment de la ciencia, el staff permanente y los colaboradores de Ciencia Nueva eran ingenieros, médicos, físicos, filósofos, epistemólogos. De manera homóloga, aquellos lectores que firman sus cartas mencionando su profesión son ingenieros, químicos, arquitectos, profesores. El nivel de 
detalle y debate en el espacio de Correo del Lector es muy alto, generando un ida y vuelta entre autores y lectores en el mismo registro de complejidad. De hecho, varios artículos provinieron de colaboraciones o pedidos específicos formulados en cartas de lectores, y muchos de los autores de artículos publicados en Ciencia Nueva se apropiaron de la sección para continuar sus discusiones (tanto entre sí como con lectores) en ese espacio. Este ida y vuelta es "una clara demostración de que la mayoría de los autores de CN leía la revista" (Ferraro, 2010:25).

El origen profesional de estos autores queda manifiesto en las características de sus textos: uso de formas impersonales, preferencia por tiempos verbales presentes o futuros, tendencia a la nominalización (Ortiz, 2009), profusión de términos técnicos (en muchos casos insuficientemente explicados para el público no especializado), inclusión de citas y bibliografía, gráficos y diagramas numerados con el epígrafe "Figura", cierto respeto por la estructura IMMRyD ${ }^{15}$, y uso de ecuaciones, entre otras. Estas huellas propias de la escritura científica son especialmente notorias en los artículos traducidos, lo que hace pensar en una edición muy leve del contenido reproducido de medios extranjeros. Como el equipo de redacción reconocía, la elaboración de la revista requería competencias comunicativas nuevas por parte de científicos, ingenieros e investigadores. Era un proceso de estar "aprendiendo a comunicarnos a través de una revista que debe ser el vehículo de ideas y opiniones definidas en un todo coherente y que además debe apoyarse en nuestra exigencia de universitarios, en nuestra propia disciplina técnica" (CN\#8, 1971:3). Con el correr de los números la revista fue innovando en sus géneros textuales, incluyendo más entrevistas, transcripciones de charlas-debate, crónicas y artículos cercanos al ensayo, la opinión, e incluso algunas sátiras humorísticas.

Por lo tanto, Ciencia Nueva se encuadraría en lo que Ciapuscio (2009), retomando a LofflerLaurian, Ilama "alta divulgación". El contenido es generalista dentro del ámbito científico (es decir, la revista no se especializa en un área particular de las ciencias), pero está dirigido a un público "culto". El núcleo de lectores meta posee cierto nivel de formación, cultura científica (o al menos un marcado interés por la CyT), y está habituado al consumo de lecturas largas, complejas y en muchos casos, técnicas. En ese sentido, la revista configura un público selectivo, es decir, se dirige a individuos con características homogéneas que los demarcan del resto de la población (Druetta y Saur, 2003) y es consciente de ello: "No es un trabajo dirigido a un público masivo y no atrae por ello la atención de quienes invierten capitales para obtener beneficios en la misma moneda" (CN\#8, 1971:3), "Ciencia Nueva es una revista independiente y por su especialización no se dirige a un público masivo" (CN\#19, 1972:5).

Puede decirse, entonces, que nuestro análisis coincide con las conclusiones que Ciencia Nueva extrajo de su encuesta. Sin embargo, relacionado a estas características del público (estudiantes o profesionales universitarios, interesados por la CyT) surge otro rasgo que no fue tenido en cuenta por la revista: el lectorado de Ciencia Nueva era eminentemente masculino. $\mathrm{O}$, al menos, el porcentaje del lectorado que se expresaba a través de cartas. De las 104 cartas publicadas, 90 (el 86\%) fueron firmadas por hombres y sólo 8 (el $8 \%$ ) por mujeres.

15 Introducción, Materiales, Métodos, Resultados, Discusión. Secciones canónicas del artículo científico. 
Esta preponderancia masculina se observa también en la autoría de los artículos de la revista. Para este trabajo, se relevaron 413 artículos en la totalidad de los 29 ejemplares. Suponiendo que de esa cantidad se descarten las editoriales y las secciones fijas, que mantenían siempre el mismo autor, quedan 306 artículos de contenido firmados. De estos, sólo 9 fueron escritos por mujeres. Desagregando esos 9, encontramos que dos (CN\#7 y \#9, 1971) corresponden a la misma autora, la doctora en Química uruguaya Lucía Bonadeo $^{16}$. La doctora en Matemática Cora Sadosky ${ }^{17}$, la geógrafa Aída Nuss de Epstein, y la doctora en Historia Hilda Sábato ${ }^{18}$ son las científicas argentinas que escribieron artículos propios (CN\#4, 1970; \#6, 1970; y \#13, 1971, respectivamente). La paleontóloga inglesa Cherrie Bramwell figura como co-autora de un artículo traducido de New Scientist (CN\#17, 1972); mientras que la psicóloga argentina Norma de Pistauro ${ }^{19}$ también es coautora de un artículo sobre medicina del trabajo (CN \#20, 1972). Otro texto es una traducción de "El lenguaje de los símbolos", de la antropóloga estadounidense Margaret Mead (CN\#24, 1973). Finalmente, el artículo restante no es un texto, sino una reproducción de las "caligrafías ilegibles" de la artista argentina Mirta Dermisache (CN\#24, 1973).

Nuevamente, se percibe cómo las condiciones de producción dejan su huella en el producto y delimitan ciertas condiciones de recepción. Pese a que la redacción y diseño de la revista estaba a cargo de mujeres, y que la presencia femenina en el equipo se fue incrementando, los puestos de director y asesores científicos siempre fueron ocupados por hombres. La consulta a científicas en calidad de expertas es muy baja y nunca se sostuvo una entrevista individual con una investigadora. Ciencia Nueva era escrita por y para hombres que disparaban contra todos los aspectos arbitrarios y alienantes del sistema científico, excepto la disparidad de género. En una entrevista titulada "Cómo hacemos La Recherche", Michel Chodkiewicz, el entonces director de la publicación francesa tomada como referencia por Ciencia Nueva, hizo la misma observación. "Hubo una decepción porque nos enteramos de que nuestro público era masculino, en la proporción del go por ciento. Yo había esperado una mayor participación de mujeres" (CN\#25, 1973:53). Esto da cuenta de una situación generalizada y estructural del campo científico a nivel internacional y no de una condición de atraso particular de la Argentina.

\section{Conclusión}

Como revista de CPC, Ciencia Nueva fue una publicación sumamente innovadora en su origen, perspectiva y estructura. Se encuadraría en un modelo de alta divulgación debido a las características de sus textos y a las competencias que exige para interpretarlos por parte de su lector modelo. Cabe preguntarse, entonces, quién era realmente el destinatario meta de Ciencia Nueva. Como analizamos en el punto 3.1.1, existían secciones fijas destinadas a difundir información a la comunidad científica-académica (cursos, congresos, becas disponibles, etc.). Por otro lado, más arriba mostramos cómo los propios investigadores que publicaban en la revista intercambiaban los roles de autores-lectores con mucha fluidez, y numerosas cartas del lector estaban firmadas por otros profesionales o especialistas. Es decir, los científicos se ubicaban tanto en el lugar de la producción como

\footnotetext{
${ }^{16}$ Podría agregarse un tercer artículo que trata sobre los temas de competencia de Bonadeo (técnicas químicas aplicadas a las artes plásticas) firmado sugestivamente con las iniciales L. B. y publicado en el número 13, noviembre de 1971. Para entonces, la autora había pasado a formar parte del staff de redacción permanente de la revista.

${ }^{17}$ Hija de Manuel Sadosky, casada con el biólogo molecular Daniel Goldstein, quien formaba parte del grupo fundador de Ciencia Nueva.

${ }^{18} \mathrm{Hija}$ de Jorge Sábato.

${ }^{19}$ Desaparecida por la última dictadura militar argentina en 1977.
} 
de la recepción. Sin embargo, Ciencia Nueva no puede bajo ningún concepto considerarse una publicación académica o un journal científico. Más allá de su voluntad de generar debate al interior de la comunidad científica, el objetivo principal de la publicación era llegar a un público más general y amplio. En ese sentido, Ciencia Nueva en tanto publicación periódica de CPC tensiona las clasificaciones de Verón. Elaborada principalmente por investigadores y consumida por un público que excedía -si bien incluía- a la comunidad científica argentina y latinoamericana, la revista buscó apelar a un público amplio, pero, intencionalmente o no, terminó incidiendo más dentro del propio campo científico.

Esta situación de producto de CPC híbrido se observa en las características del lectorado de Ciencia Nueva. Como publicación periódica gráfica, la revista propuso un contrato de lectura que fue rápidamente aceptado por un público nítidamente definido: estudiantes o profesionales, con hábitos de consumo cultural elevados, interesados o participantes en ámbitos de CyT y política nacional, residentes en Argentina (en especial en CABA) o países limítrofes, y mayoritariamente hombres. Los cambios detectados en el contrato de lectura obedecen principalmente a una explicitación de la posición política de la revista. Todos los elementos que componen las estrategias de enunciación (principalmente la redacción de las editoriales, los temas de tapa y el uso de recursos gráficos) acompañan este cambio, que no repercutió negativamente en la cantidad de lectores, más bien lo contrario. Ciencia Nueva consiguió fidelizar a este lectorado a partir de la generación y cumplimiento de ciertas expectativas en cuanto a su periodicidad de aparición, actualidad de los temas tratados, profundidad de análisis, relevancia intelectual de los colaboradores, y pluralidad de voces. Asimismo, la revista continuamente instaba al diálogo entre productores y lectores. Su línea editorial no impedía que se publicaran intervenciones ideológicamente opuestas si la calidad de los textos lo ameritaba y sus autores estaban abiertos al debate.

La gran mayoría de los anunciantes que sostenían la revista con sus publicidades eran de origen argentino, pero los de origen extranjero tenían una fuerte presencia por el tamaño y ubicación estratégica de sus avisos. La evidencia parece sugerir que los anunciantes de origen extranjero estaban en condiciones de afrontar gastos mayores en publicidad. Por otro lado, entre los anunciantes argentinos se observa una mayor fidelidad hacia la revista, ya que son los que conformaban por amplia mayoría el núcleo de publicidades recurrentes. Las características propias del discurso publicitario presentan una imagen glorificada de las potencialidades de la ciencia y -sobre todo- la tecnología, que no se condice totalmente con la línea crítica de la revista. No obstante, el contrato de lectura entre el medio y el lectorado establece que la publicidad se interprete como un discurso separado y no asimilable al de la revista en sí. Asimismo, la amplia publicidad de anunciantes argentinos hace pensar en Ciencia Nueva como una "vidriera" para empresas nacionales de base tecnológica y otras publicaciones periódicas científicas e intelectuales, del mismo modo en que constituyó un espacio de encuentro para los pensadores relacionados con el PLACTED.

Ciencia Nueva constituyó una novedad dentro de los campos académico, científico y editorial argentinos ya que no se trataba de una publicación orgánica de alguna institución científica en particular. La revista era conducida por investigadores formados en Argentina, muchos de quienes regresaban al país luego de estancias en el exterior. El equipo editorial abrevó de estas experiencias para rescatar rasgos de revistas extranjeras y para consolidar una fuerte red de corresponsales, permisos de traducción y reproducción de artículos. Además, durante estas estadías, y mediante el intercambio con otros exiliados latinoamericanos, la política nacional, particularmente el peronismo, cobró otra dimensión para este grupo. Por lo tanto, la revista que construyeron jamás disoció el pensamiento científico del político, como dijera Varsavsky (CN\#12, 1971). En efecto, Ciencia Nueva 
integraba periodismo y divulgación científica de alto nivel con discusiones sobre política científica y modelos de desarrollo tecnológicos a nivel latinoamericano.

Si bien la coyuntura de los años '6o-'70 fue lo que motivó y posibilitó el surgimiento y mantenimiento de la revista, los artículos publicados resultan de una riqueza teórica e ideológica tal que permiten ser recuperados y revalorizados décadas después. A casi 50 años de su aparición, las preocupaciones expresadas en Ciencia Nueva siguen vigentes. En definitiva, Ciencia Nueva no sólo puso a disposición del público las últimas novedades y desarrollos de las ciencias, sino que representó un esfuerzo significativo en abrir el juego para el siempre necesario debate sobre cuestiones vinculadas a una agenda regional de políticas de ciencia y tecnología. Desde una postura crítica, la revista ensayó algunas respuestas para su época; pero, lejos de estar zanjadas, estas preguntas vuelven a aparecer en el contexto actual. Por este motivo consideramos que el análisis efectuado sobre la estructura de Ciencia Nueva y su relación con su lectorado puede ser una base para estudiar en clave comparada los contratos de lectura de publicaciones pasadas y actuales dedicadas a la CPC, profundizar sobre semiótica de la imagen y el discurso publicitario, o indagar en los efectos de discurso producidos por distintos medios sobre la ciencia y la tecnología. 


\section{Referencias bibliográficas}

ALCíBAR, Miguel (2015): "Comunicación pública de la ciencia y la tecnología: una aproximación crítica a su historia conceptual". Arbor, vol.191, N773: a242. Madrid, Consejo Superior de Investigaciones Científicas. doi: 10.3989/arbor.2015.773n3012

BORCHES, Carlos (2014): "Ciencia Nueva, la revista científica de los '70". La Ménsula, año 7, $\mathrm{N}^{\circ} 18$. Buenos Aires, Programa de Historia de la Facultad de Ciencias Exactas y Naturales, pp.1-6.

CASAS GUERRERO, Rosalba (2004): "Conocimiento, tecnología y desarrollo en América Latina". Revista Mexicana de Sociología, vol.66. México DF, Universidad Autónoma de México, pp. 255-277. doi: 10.2307/3541453

CAZAUX, Diana (2010): Historia de la divulgación científica en Argentina. Buenos Aires, Teseo Editorial.

CIENCIA NUEVA (1970-1974). Números 1-29. Buenos Aires, Editorial Ciencia Nueva. Disponibles en https://issuu.com/ciencianueva

CIAPUSCIO, Guiomar (2009): "El concepto de norma y variedad en revistas de divulgación científica de Argentina y México". IV Coloquio de Investigadores en Estudios del Discurso y I Jornadas Internacionales sobre Discurso e Interdisciplina: Una invitación al debate. Córdoba, Universidad Nacional de Córdoba, 16-18 de abril.

DEPARTAMENTO DE ESTADO DE LOS ESTADOS UNIDOS (1977): CAS Report Supplement I. Additional Information on the Situation of Argentine Scientists and University Professors.

DRUETTA, Santiago y SAUR, Daniel (2003): Manual de producción de medios gráficos. Córdoba, Editorial Comunicarte.

FAIERMAN, Florencia (2017): "'Ciencia Nueva': de revista de ciencia y tecnología a revista de vanguardia". Cuadernos del CEL, vol.2, $\mathrm{N}^{\circ}$. Buenos Aires, Universidad Nacional de San Martín, pp.14-26.

FELD, Adriana (2011): "Las primeras reflexiones sobre la ciencia y la tecnología en la Argentina: 1968-1973". Redes, vol.17, N³2. Buenos Aires, Universidad Nacional de Quilmes, pp.185-221.

FERRARO, Ricardo (2010): Ciencia Nueva: debates de hoy en una revista de los '70. Buenos Aires, edición de autor.

HERRERA, Amilcar (2015 [1970]). Ciencia y política en América Latina (1a ed.). Buenos Aires, Biblioteca Nacional.

HURTADO DE MENDOZA, Diego (2011): "Surgimiento, alienación y retorno: el pensamiento latinoamericano en ciencia, tecnología y desarrollo". Voces en el Fénix, N8. Buenos Aires, Facultad de Ciencias Económicas, Universidad de Buenos Aires, pp. 20-27. 
HURTADO DE MENDOZA, Diego, y FELD, Adriana (2010): "La revista Mundo Atómico y la 'nueva Argentina científica"'. En PANELLA, Claudio y KORN, Guillermo (eds.): Ideas y debates para la Nueva Argentina. Revistas culturales y políticas del peronismo (1946-1955). La Plata, Editorial de la Universidad Nacional de La Plata, pp.210-228.

JIMÉNEZ BECERRA, Javier (2010): "Origen, desarrollo de los estudios de Ciencia, Tecnología y Sociedad y su perspectiva en América Latina", en MANCERO, Mónica y POLO, Rafael (comps.): Ciencia, política y poder. Debates contemporáneos desde Ecuador. Quito, FLACSO, pp.103-129.

KREIMER, Pablo (1998): "Publicar y castigar. El paper como problema y la dinámica de los campos científicos". Redes, vol.5, N²12. Buenos Aires, Universidad Nacional de Quilmes, pp.51-73.

KREIMER, Pablo (2007) "Social Studies of Science and Technology in Latin America: A Field in the Process of Consolidation". Science, Technology and Society, vol.12, No 1. SAGE Publications, pp.1-9.

ORTIZ, Renato (2009): La supremacía del inglés en las ciencias sociales. Buenos Aires, Editorial Siglo XXI.

VERÓN, Eliseo (1985): "El análisis del 'Contrato de Lectura', un nuevo método para los estudios de posicionamiento de los soportes de los media", en Les Médias: Expériences, recherches actuelles, applications. París, IREP.

VERÓN, Eliseo (1993): La semiosis social. Fragmentos de una teoría de la discursividad. Barcelona: Gedisa.

VERÓN, Eliseo (1998). "Entre la epistemología y la comunicación". CIC Cuadernos de Información y Comunicación, $\mathrm{N}^{\circ} 4$. Madrid, Universidad Complutense de Madrid, pp.149155 .

VESSURI, Hebe (1987): "The social study of science in Latin America". Social Studies of Science, vol.17, $\mathrm{N}^{\circ} 3$. SAGE Publications, pp.519-554. 